\title{
NEW PHYSICAL EFFECTS IN METAL DEUTERIDES
}

\author{
Peter L. Hagelstein, ${ }^{1}$ Michael C. H. McKubre, ${ }^{2}$ David J. Nagel,${ }^{3}$ \\ Talbot A. Chubb, ${ }^{4}$ and Randall J. Hekman ${ }^{5}$ \\ ${ }^{1}$ Massachusetts Institute of Technology, Cambridge, $M A$ \\ ${ }^{2}$ SRI International, Menlo Park, CA \\ ${ }^{3}$ The George Washington University, Washington DC \\ ${ }^{4}$ Research Systems Inc., Arlington, VA \\ ${ }^{5}$ Hekman Industries, LLC, Grand Rapids, MI
}

The experimental evidence for anomalies in metal deuterides, including excess heat and nuclear emissions, suggests the existence of new physical effects.

\section{INTRODUCTION}

Following the initial claims of $1989,{ }^{1,2}$ the body of research on anomalous effects in metal deuterides has grown to include thousands of papers on a wide spectrum of topics. DoE, to facilitate their review of this set of research, has asked for the preparation of the following summary. The entire body of research is not addressed. Rather, a subset of research from two areas is presented: selected issues associated with excess heat production in deuterated metals, and a brief discussion of some aspects of nuclear emissions from deuterated metals.

\section{EXCESS HEAT EFFECTS IN FLEISCHMANN-PONS EXPERIMENTS}

In the simplest sense, the Fleischmann and Pons experiment is an aqueous electrochemical experiment in which a palladium cathode is loaded with deuterium in a heavy water electrolyte. If the associated conditions are suitable, an excess heat ${ }^{\mathrm{a}}$ effect can be observed (for example, see Figure 1). In 1989, there developed both interest and concern regarding the measurement of excess energy and the conditions under which the excess heat effect could be observed. In the years following the initial announcement, it was easier for most to believe that the effect was due to calorimetric errors than due to new physics. However, excess heat has been observed with a variety of calorimeters based on varying operating principles and by different groups in different labs, all largely with similar results. The hypothesis that the excess heat effect arises only as a consequence of errors in calorimetry was considered, studied, tested, and ultimately rejected. A brief discussion of calorimetric issues is provided in Appendix A (see also a recent more general discussion by Storms ${ }^{3}$ ). The conditions under which the excess heat effect occurs remain of interest. Much has been learned since 1989. We consider briefly in what follows some of the

${ }^{a}$ Excess power is the output power minus the input power as discussed in Appendix A. The time integral of excess power is excess energy, which is observed experimentally as excess heat. 


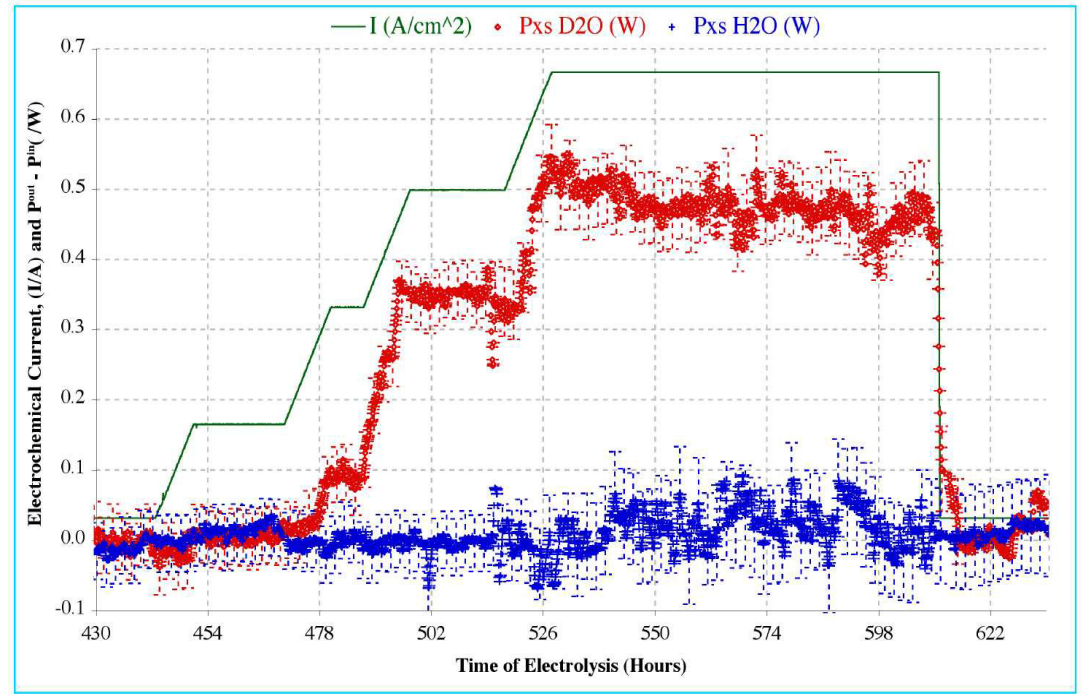

Figure 1. Excess power in Fleischmann-Pons experiments as a function of time in twin cells and calorimeters, driven with a common current, one with heavy water and one with light water.

factors that have been identified. ${ }^{\mathrm{b}}$

\subsection{Total Excess Energy Production}

The total excess energy produced in the Fleischmann-Pons experiment can greatly exceed what might be expected from chemical effects. ${ }^{1,4}$ The energy density is customarily quoted relative to the total cathode volume ${ }^{\mathrm{c}}$ corresponding to the conclusion that the excess heat effect has its origin within the metal deuteride based on measurements of cathode temperature rise and the establishment of temperature gradients in electrolytic and gas calorimetric experiments. Gozzi and coworkers reported ${ }^{5}$ excess energy production at the level of $130 \mathrm{MJ} / \mathrm{cm}^{3}$. The SRI group quoted a value of $45 \mathrm{MJ} / \mathrm{mol}$ for a measurement in a closed cell flow calorimeter, which is about $450 \mathrm{eV} /$ atom of $\mathrm{Pd} .{ }^{6}$ There are a great many reports of energy production at this general level, and some at much higher levels as well.

\subsection{Excess Heat and Loading}

Early publications by Fleischmann and Pons implied that the phenomenon they were studying was conditioned. From the material then available, it was not easy to deduce a complete set of necessary and sufficient conditions to initiate the excess heat effect. Little effort was made in early replication attempts to measure or report the bulk, interfacial and stimulus conditions employed. By the time of the first International Conference (ICCF1 in 1990), an effort was underway to evaluate systematically the various

\footnotetext{
${ }^{\mathrm{b}}$ The excess heat effect itself is consistent neither with a conventional D+D fusion reaction mechanism, nor with any other nuclear reaction mechanism that appears in textbooks or in the mainstream nuclear physics literature. The existence of an excess heat effect with no commensurate energetic nuclear products rules out whole classes of potentially relevant reaction mechanisms, but does not provide guidance as to what kind of process is occuring. The observation of ${ }^{4} \mathrm{He}$ correlated with excess energy, which is discussed later, is suggestive that the reaction mechanism is consistent with $\mathrm{D}+\mathrm{D} \rightarrow{ }^{4} \mathrm{He}$, but sheds little light on how such reactions might occur.

${ }^{\mathrm{c}}$ Whether the excess heat is a surface or bulk effect has not yet been clarified in the Fleischmann-Pons experiment. There exist rather good arguments which support the hypothesis that the reactions take place near the surface, but this discussion is beyond the scope of this manuscript.
} 


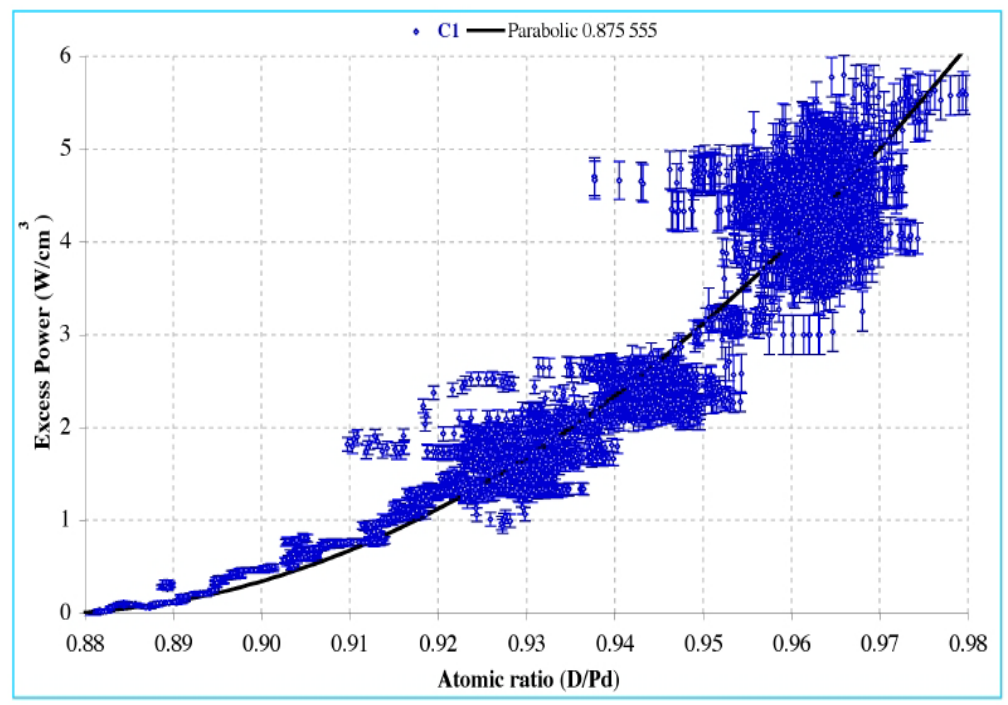

Figure 2. Excess power density in $\mathrm{W} / \mathrm{cm}^{3}$ versus average $\mathrm{D} / \mathrm{Pd}$ atomic ratio measured from the axial resistance for a Johnson Matthey wire cathode $30 \mathrm{~cm}$ long and $1 \mathrm{~mm}$ diameter in $1.0 \mathrm{M} \mathrm{LiOD}$ containing $200 \mathrm{ppm} \mathrm{Al}$.

parameters of the effect. With the development ${ }^{7}$ and adoption ${ }^{8}$ of bulk resistivity and other methods ${ }^{9}$ as in-situ probes of the Pd cathode composition, it was quickly recognized that the Fleischmann and Pons effect occurred in $\mathrm{Pd}$ wire cathodes only when very high average levels of loading (D:Pd atomic ratio) were achieved in the Pd bulk. ${ }^{\mathrm{d}}$ Figure 2 shows the measured correlation between thermal power production (in excess of known power input) and D:Pd bulk atomic ratio determined in-situ from the measured cathode resistance. The effect appears to increase approximately parabolically above a threshold loading of $\mathrm{D} / \mathrm{Pd} \approx 0.875$. A very similar result with a slightly lower threshold was presented and published simultaneously by Kunimatsu et al. ${ }^{9,10}$ based on independent experiments carried out at IMRA Japan (Hokkaido). Such high loading is accompanied by high internal pressure, and it is necessary for the cathode to be able to withstand this in Fleischmann-Pons experiments. ${ }^{11}$

This loading requirement in the basic Fleischmann-Pons experiment is thought to be a general precondition for the effect in Pd wire cathodes. ${ }^{\mathrm{e}}$ An analysis of 49 calorimetric results obtained at SRI in 1990 and 1991 showed that in no case was a calorimetric imbalance observed (19 examples) where an electrode failed for whatever means to achieve a bulk average $\mathrm{D} / \mathrm{Pd}$ loading of 0.9 . However, all electrodes achieving a loading of 0.95 or greater (15) exhibited a heat excess more than 3 times the measurement uncertainty $(\sigma)$, in many cases many tens of $\sigma$ larger. Example of such heat excess is shown in Figures 1 and 3. For the cells with cathodes achieving a maximum loading between 0.90 and 0.95 , approximately half manifested measurable excess heat and half did not.

The equilibrium spacing of deuterons in $\mathrm{PdD}$ is greater than in $\mathrm{D}_{2}$, so the proximity of deuterons at high loading alone is not expected to promote an excess heat effect. The pair-wise fusion rate of deuterons in PdD or in other metal deuterides is too small by tens of orders of magnitude to be observable. ${ }^{13}$ The notion that deuterons are somehow being squeezed together, so as to fuse at high loading or high fugacity

\footnotetext{
${ }^{\mathrm{d}}$ In the SRI experiments, an additional requirement was noted, namely that the loading needed to be maintained for several weeks to a month, which was at least 10 times longer than the deuterium diffusional time constant. This is consistent with the experience of other groups. ${ }^{12}$ This requirement is not an absolute requirement, as there exist experimental results with shorter initiation times for cathodes of other geometry and surface deposited films.

eHigh loading in these room temperature experiments is consistent with the presence of a high deuterium chemical potential, which would allow deuterons to reach higher energy states in the metal deuteride.
} 


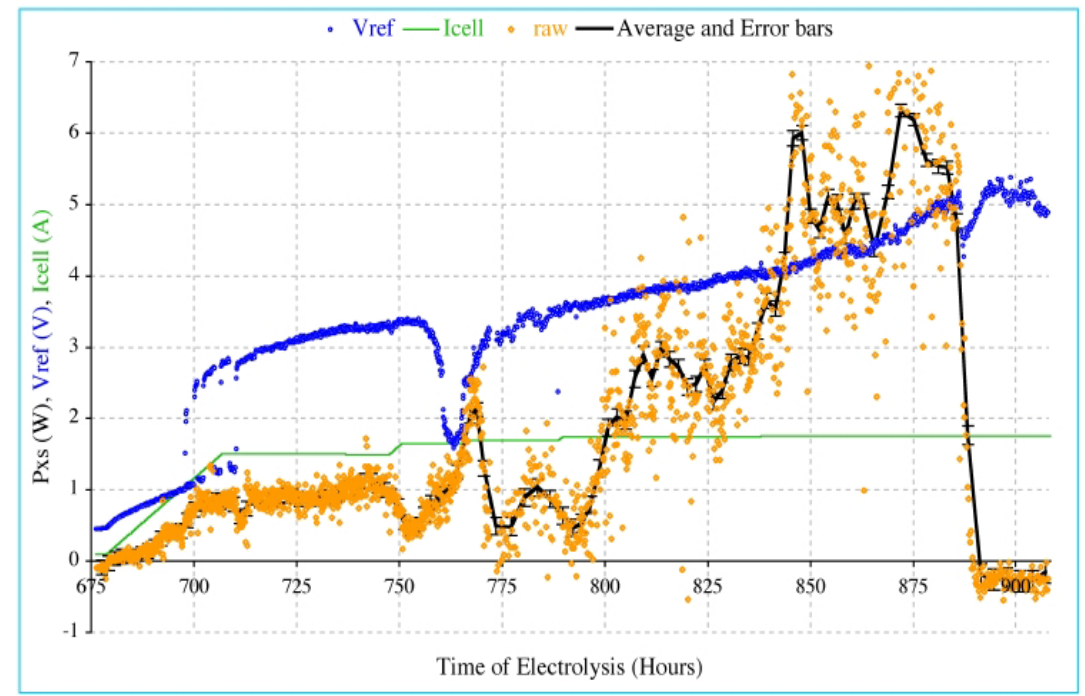

Figure 3. Excess power $\left(P_{x s}\right)$, reference voltage $\left(V_{\text {ref }}\right)$ and cell electrochemical current $\left(I_{\text {cell }}\right)$ as a function of time (hours) for an Englehard Pd wire cathode $3 \mathrm{~cm}$ long and $3 \mathrm{~mm}$ in diameter in 1.0M LiOD containing $200 \mathrm{ppm} \mathrm{Al.}$

in these experiments, is not considered a plausible explanation.

\subsection{Surface Chemical Potential}

Fleischmann and Pons recognized the surface chemical potential of deuterium as the variable most critically associated with the effect they were studying. If the bulk and surface are at equilibrium then the surface chemical potential can be inferred from a measurement of the bulk loading. The situation relevant to the Fleischmann-Pons effect, however, often involves inhomogeneous loading and the presence of important deuterium fluxes. Under these conditions a measure of the average composition reflects only the lower limit of the surface chemical potential for a dynamically loading cathode.

Electrochemists have long used the reference voltage as a means to measure a species' chemical potential. ${ }^{14}$ Basically, the potential difference is measured between the electrode of interest and another having defined potential (the reference electrode) either in the presence of a steady current or at open circuit. Fleischmann and Pons advocated this method as early as $1990 .{ }^{15}$ Others have made use of this method as a diagnostic in relation to the excess heat effect. ${ }^{16,17,18,19}$

Figure 3 plots an early result at SRI where the cell current, reference voltage and excess power were recorded simultaneously. In this case the reference voltage was measured without interruption of current, and the presence of a finite electrolyte resistance between the cathode and reference electrodes results in voltage offset proportional to current. It is clear, however, that the dynamics of the reference potential more closely correlate with the excess power than with the cell current. Unfortunately the electrode surface potential is determined by other species in addition to deuterium. The adsorption of $\mathrm{Li}$, for example, is strongly reflected in the potential plotted in Figure 3, and the maintenance of a high potential at near zero excess power at the right of this figure was thought to reflect the presence of a lithium rich, blocking surface film deposited on the cathode surface. The latter ambiguity is removed if the reference potential is measured with current interruption. ${ }^{18}$ 


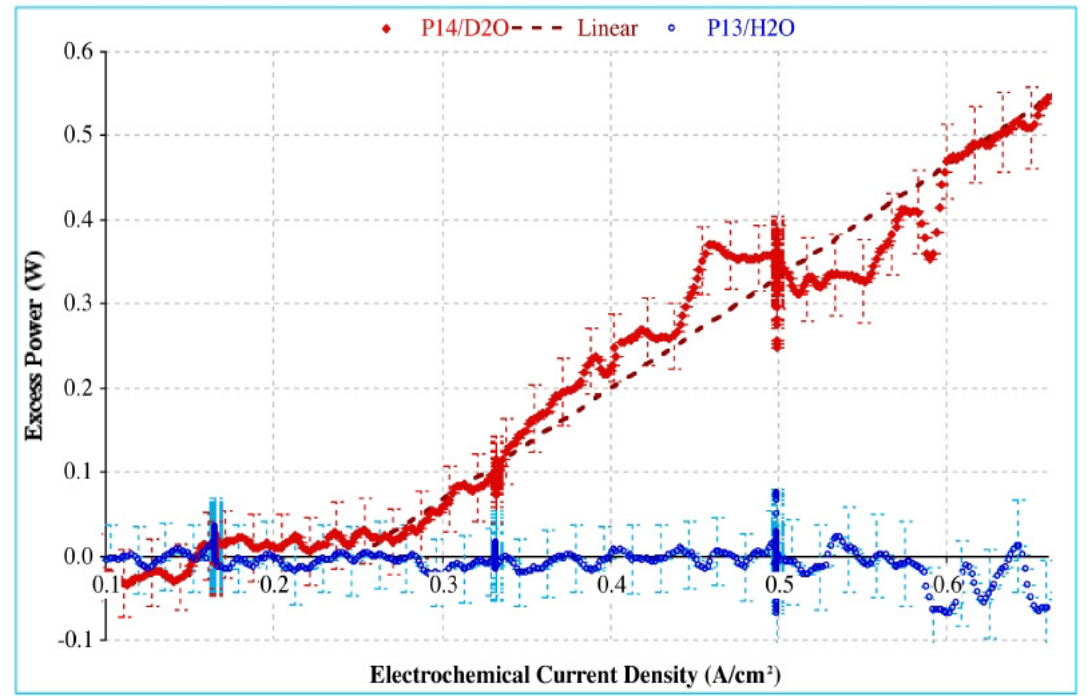

Figure 4. Excess power as a function of current density for Fleischmann-Pons cells with heavy water and with light water.

\subsection{Temperature Dependence}

A strong sensitivity of excess heat production on the operating temperature was noted and exploited early on by Fleischmann and Pons, who developed an interesting protocol in which the temperature was allowed to rise following the onset of an excess heat effect. ${ }^{20}$ The heat was found to increase over the course of a calibration heat pulse, which is attributed to a thermal positive feedback effect. ${ }^{21,22}$ Others have noted such a temperature effect. ${ }^{23}$ This basic effect was studied by Storms, ${ }^{24}$ and the results expressed in a form consistent with

$$
P_{\text {excess }}=P_{0} e^{-E_{a} / k_{B} T}
$$

where $E_{a}$ is an equivalent activation energy that was found to be about $15 \mathrm{Kcal} / \mathrm{mol}$ (about $\left.670 \mathrm{meV}\right){ }^{\mathrm{f}}$ The observed small activation energy is thought to be associated with creating the proper chemical environment and not associated directly with the nuclear process.

\subsection{Excess Heat and Current Density}

The identification of the D/Pd loading requirements as necessary criteria did not bring an understanding of the Fleischmann and Pons effect. Moreover, an initiation effect was noted that has nothing to do with D loading, an explanation for which was proposed only recently. Electrochemical current density was initially reported by Fleischmann and Pons as having a threshold effect on excess heat production that is completely independent of its effect on loading, ${ }^{4}$ and this was later widely studied and confirmed. . $, 6,26,27,28,10,24,29,30,31$ Evidence of this current threshold behavior can be seen in Figure 3, and more directly in Figure 4, which shows calorimetric results from two identical cells, one with $\mathrm{D}_{2} \mathrm{O}$ and one with $\mathrm{H}_{2} \mathrm{O}$, operated electrically in series, while interrogated with the same measurement system. ${ }^{27}$ An approximately linear increase in excess power with a threshold of about $265 \mathrm{~mA} \mathrm{~cm}{ }^{-2}$ can clearly be seen for the $\mathrm{Pd}$ cathode operated in $\mathrm{D}_{2} \mathrm{O}$. Data for the $\mathrm{H}_{2} \mathrm{O}$ cell do not deviate from calorimetric

\footnotetext{
${ }_{\mathrm{f}} \mathrm{A}$ similar rapid increase in temperature was noted by Case in a gas loading experiment at elevated temperature. The effective activation energy was reported to be $13 \mathrm{Kcal} / \mathrm{mol}$ (about $560 \mathrm{meV}) .{ }^{25}$
} 


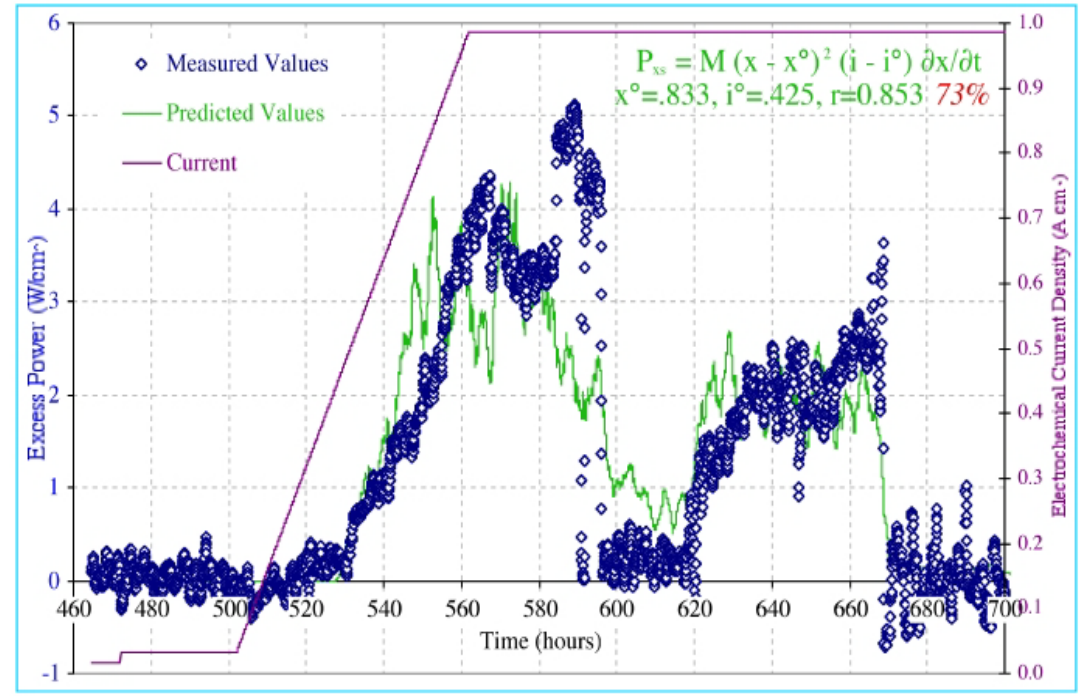

Figure 5. Excess power as a function of time and fitting function for a Johnson Matthey Pd wire cathode $10 \mathrm{~cm}$ long and $1 \mathrm{~mm}$ diameter in $1.0 \mathrm{M}$ LiOD containing $200 \mathrm{ppm} \mathrm{Al}$.

balance; various excursions reflect only transients following changes in input power. In no case was the Fleischmann and Pons effect observed to occur in cells containing $\mathrm{H}_{2} \mathrm{O}$ as the major component at SRI, and excess heat measured in $\mathrm{D}_{2} \mathrm{O}$ cells was observed to decrease to zero upon substantive addition of $\mathrm{H}_{2} \mathrm{O}$.

\subsection{Deuterium Flux and Triggering Issues}

The excess heat effect is often observed to be stimulated by changes in the experimental conditions. Fleischmann and Pons noticed in their initial work that the excess heat effect was occasionally initiated or improved with the application of a heat pulse, which can be considered as a transient change in conditions within the present argument. At SRI, one of the techniques used with success to initiate a heat pulse was to alter the current density, either through sudden changes or through ramps (as in Figure 5). Takahashi introduced a protocol in which the current density was alternated between low and high values. ${ }^{32,33}$ Bockris described a regimen in which the current periodically changed direction. ${ }^{34}$ Yamaguchi described an experiment involving vigorous outgassing of deuterium from a rapidly heated metal deuteride sample. ${ }^{35,36,37}$ The application of an axial current in a wire or cathode can be used to drive a significant deuterium flux against the electronic current. ${ }^{38}$ This effect was exploited by Celani and coworkers, ${ }^{39,40}$ and by Preparata ${ }^{41}$ who reported excess heat and other effects with a high axial current.

Quantitative evidence indicating that deuterium flux plays an important role in determining the excess heat in a Fleischmann-Pons cell was found at SRI. ${ }^{42}$ A purely empirical function was found to describe the excess heat observed for $1 \mathrm{~mm}$ diameter Pd cathodes. This function, and its fit to experimental data, are shown in Figure 5. After initiation, excess power was found to be proportional to the product of three terms: (i) the square of the loading above a threshold value $\left(x-x_{0}\right)^{2}$; (ii) the electrochemical current above a threshold; and (iii) the flux of deuterium through the interface, irrespective of direction, measured as the time derivative of the average $\mathrm{D}$ loading, $|\delta x / \delta t| . \mathrm{g}$

${ }^{g}$ The empirical fit in the absence of a flux term had successfully matched much experimental data previously. A cathode 
Incoming deuterium produces a flux that increases the loading, which should improve things according to the discussion above. But experiments seem to show that deuterium flux makes a difference, independent of whether it is incoming, outgoing, axial, or traversing. ${ }^{43}$ One question of interest concerns the functionality of the flux: what is it about the flux that makes a difference? Another interesting question, independent of any understanding of the functionality, is whether the effect of deuterium flux can be augmented or replaced by other kinds of stimulation. This question opens the door to a very much larger discussion that we are not able to pursue here. The general issue of triggering has been of interest since the early 1990s ${ }^{44}$ and occupied a central place at recent international conferences. ${ }^{43,45,46,47,48,49}$

\section{HELIUM AND EXCESS HEAT}

Much effort has been devoted to the search for reaction products that could be associated with the excess heat. It soon became clear that there are insufficient chemical reaction products to account for the excess heat by several orders of magnitude. Attention has been directed to the search for nuclear "ash" in amounts commensurate with the energy measured. The problem is more difficult than in the case of chemical reactions as no similar processes are known.

Searches for neutrons, tritons, and other energetic emissions in quantitative association with the excess heat effect have uniformly produced null results. ${ }^{5}$ The absence of quantitative energetic emissions leads to the conjecture that the new process is somehow converting nuclear energy directly to heat. There have been numerous consequences of this within the field, one of which is that people have historically been motivated to maximize the energy produced in excess heat experiments (and not efficiency ${ }^{19}$ ) in the hope of maximizing the reaction products, so that they might be identified. There have been many assays performed on cathodes before and after excess heat production, seeking the presence of new elements or isotope shifts. ${ }^{50,51,52}$ Although there appears to be evidence that supports the existence of both elemental and isotopic anomalies near the cathode surface in some experiments, it is generally accepted that these anomalies are not the ash associated with the primary excess heat effect. The main focus of attention has been on helium as the primary nuclear reaction product. ${ }^{53}$

\subsection{Correlation of Excess Heat and Helium}

Numerous investigators have sought and, in many cases, found ${ }^{4} \mathrm{He}$ in different environments including in the gas phase, ${ }^{54,55,56,57,58,59,60,107}$ dissolved in the cathode metal, ${ }^{61,62,63,64,65,66}$ and emitted as charged particles. ${ }^{67,68}$ If helium were created in the cathode interior, then one might expect to see helium dissolved in the metal. If helium were produced near the surface, then perhaps it would show up in the surrounding gas. The presence of quantitative energetic helium would be expected to produce an associated Bremsstrahlung x-ray emission. However, there is no evidence for such signals in quantitative measure with what might be expected for a primary excess heat mechanism.

The first and historically most important experiments were performed by Miles et al., to correlate the helium content of gas produced by electrolysis $\left(\mathrm{D}_{2}\right.$ or $\mathrm{H}_{2}$, and $\left.\mathrm{O}_{2}\right)$ with the average heat excess during the interval of sampling. Because of the very low ${ }^{4} \mathrm{He}$ concentration expected and observed (1$10 \mathrm{ppb}$ ) extensive precautions were taken to ensure that samples were not substantially contaminated from the large ambient background $(5.22 \mathrm{ppm})$. In an initial series of experiments, later replicated several times ${ }^{55,69}$ eight electrolysis gas samples collected during episodes of excess heat production in two identical cells showed the presence of ${ }^{4} \mathrm{He}$ whereas six control samples gave no evidence for ${ }^{4} \mathrm{He}$.

exhibited a "breathing mode" during an excess heat burst in which the deuterium loading varied roughly sinusoidally around a high value. The excess heat data in this case was not matched well by the earlier empirical fit. The fit was greatly improved with the inclusion of a new factor proportional to the magnitude of the flux. 


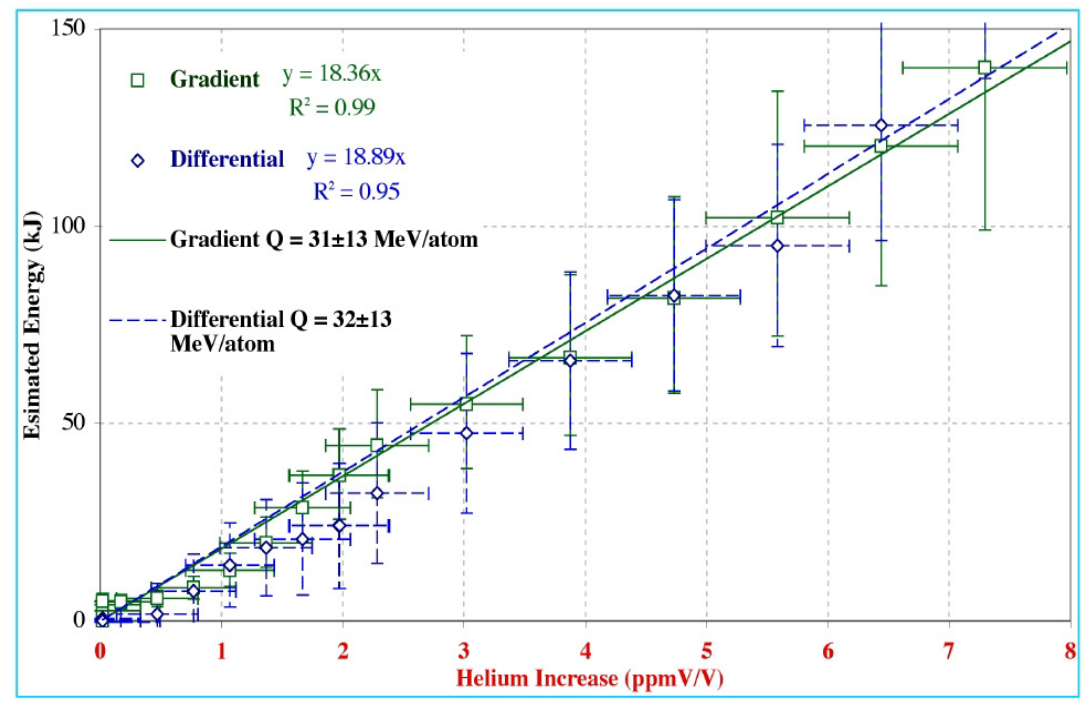

Figure 6. Excess energy determined by gradient (boxes) and differential (diamonds) calorimetric methods plotted against the increase in ${ }^{4} \mathrm{He}$ concentration in a metal-sealed helium leak-tight vessel. The experiment was performed by heating palladium on carbon hydrogenation catalyst materials to $\sim 190^{\circ} \mathrm{C}$ in $\sim 3$ atmospheres of $\mathrm{D}_{2}$ gas pressure (see Appendix B).

These results were only semi-quantitative, although the statistical significance of these and later results were profound. Because of questions related to the helium permeability of sample vessels and cells, these results were taken simply as suggesting a nuclear origin and mechanism for the Fleischmann and Pons effect.

Later work by Miles and Bush using sealed metal vessels, and by McKubre ${ }^{70}$ and Gozzi ${ }^{71}$, confirmed that ${ }^{4} \mathrm{He}$ is presented to the gas phase above the electrolyte of a cathode demonstrating the Fleischmann and Pons effect. ${ }^{\mathrm{h}}$ Gozzi presented some very striking results, ${ }^{71}$ in which bursts of excess energy were time-correlated with bursts of ${ }^{4} \mathrm{He}$ observed in the gas stream. ${ }^{i}$ When compared one at a time, the number of helium atoms detected per burst was on the order of what might be expected from $23.8 \mathrm{MeV}$ per $\mathrm{D}+\mathrm{D}$ reaction, but with a variation between 0.25 and 1.0 of this amount. If the energy production in these experiments is in fact due to a reaction mechanism consistent with $\mathrm{D}+\mathrm{D} \rightarrow{ }^{4} \mathrm{He}+23.8 \mathrm{MeV}$, then it seems that some of the helium may enter the gas stream and some remain within the metal. Several important conclusions can be drawn from the studies cited above:

- The rate of helium production (atoms/s) varies linearly with excess power (see Figure 6).

- The amount of helium observed in the gas stream is generally within a factor of about 2 less than would be expected for a reaction mechanism consistent with $\mathrm{D}+\mathrm{D} \rightarrow{ }^{4} \mathrm{He}$.

- Helium is partially retained, and dissolved helium is released only slowly to the gas phase for analysis.

Recent work at ENEA Frascati also supports these conclusions. ${ }^{72,73}$ Excess heat and helium observations consistent with a $\mathrm{D}+\mathrm{D} \rightarrow{ }^{4} \mathrm{He}+23.8 \mathrm{MeV}$ (heat) reaction mechanism, in a metal deuteride near room temperature, stands in stark contrast to the $\mathrm{d}(\mathrm{d}, \gamma)^{4} \mathrm{He}$ reaction known from nuclear physics.

\footnotetext{
${ }^{\mathrm{h}}$ Issues relating to sampling, leakage, and mass spectrometry are out of the scope of this summary, but are considered in the literature.

${ }^{\mathrm{i}}$ Reasonably prompt ${ }^{4} \mathrm{He}$ appearing in the gas stream is interpreted by some as supporting the notion of the excess heat effect being a surface effect rather than a volume effect.
} 


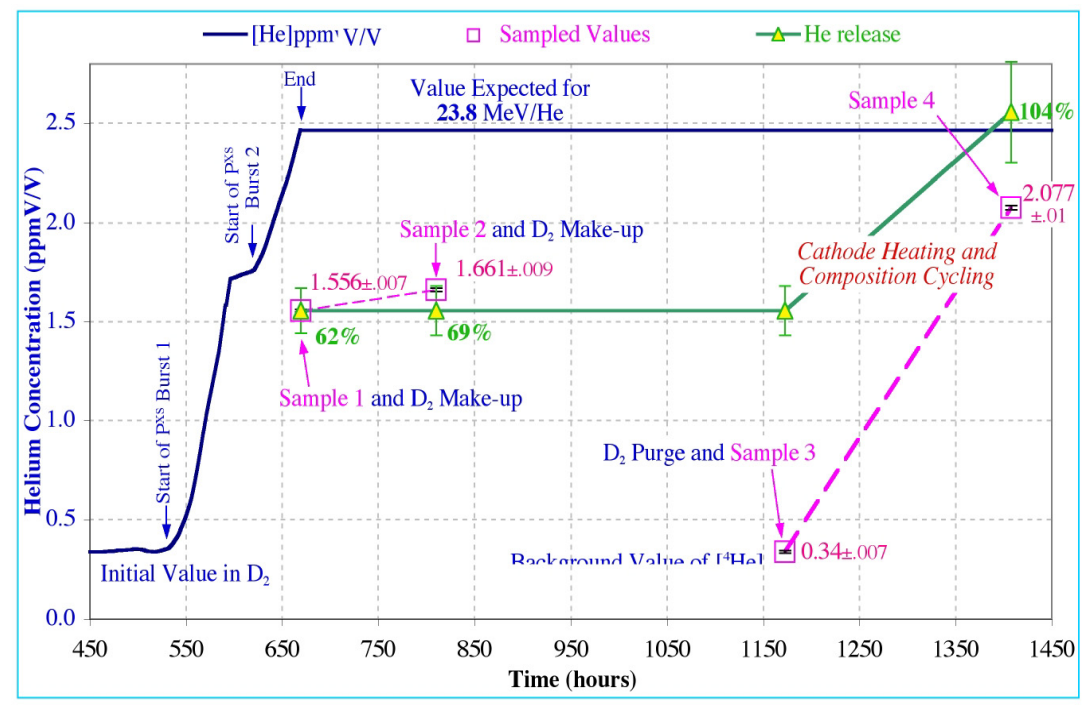

Figure 7. Results for ${ }^{4} \mathrm{He}$ measurements associated with the excess heat results presented in Figure 5 , as discussed in the text. The concentration of helium and gas sampling times are indicated by squares, and the fraction of that expected for a $23.8 \mathrm{MeV} /{ }^{4} \mathrm{He}$ atom by triangles.

\subsection{Reaction $Q$ Value}

As the loss of deuterium in association with excess heat is not presently observable, and since there are no commensurate energetic reaction products, the argument in support of reaction mechanisms consistent with $\mathrm{D}+\mathrm{D} \rightarrow{ }^{4} \mathrm{He}$ is indirect. One can measure energy production, and assay for ${ }^{4} \mathrm{He}$ in the gas stream or the solid, with uncertainties introduced in the reaction energy $Q$ because all of the helium produced may not be accounted for in the measurement. Experiments are prefered in which a total inventory of the helium is made in order to improve the accuracy of the reaction $Q$ value measurement. To this end, we discuss briefly an experiment in which helium was measured in the gas stream, and an additional effort was made to drive the helium out of the metal.

The experiment under consideration was performed at SRI, and the excess heat measured is illustrated in Figure 5. The experiment was performed in a helium leak-tight, all-metal and metal gasketed calorimeter. Samples were transferred in metal gas sample flasks to be analyzed for ${ }^{4} \mathrm{He}$ by the U.S. Bureau of Mines at Amarillo, Texas. ${ }^{70}$ The initial value of ${ }^{4} \mathrm{He}$ was $0.34 \pm 0.007 \mathrm{ppmV} / \mathrm{V}$ in the $\mathrm{D}_{2}$ gas used to charge the cell.

Figure 7 traces the history of the cell, M4, from four helium samples taken after excess power was observed. The upper solid line is the expectation for helium concentration presuming: (i) an initial value of $0.34 \mathrm{ppmV} / \mathrm{V}$, and (ii) that ${ }^{4} \mathrm{He}$ is produced in a reaction which delivers $23.8 \mathrm{MeV}$ of thermal energy to the calorimeter. The first gas sample taken shortly following the second heat burst of Figure 5 yielded a value of $1.556 \pm 0.007 \mathrm{ppmV} / \mathrm{V}^{4} \mathrm{He}$, which is about $62 \%$ of its expected value, and consistent with the earlier observations by Miles, Bush and collaborators, ${ }^{55}$ and also Gozzi and collaborators. ${ }^{71} \mathrm{~A}$ second sample taken about six days after the first showed a measurable increase in ${ }^{4} \mathrm{He}$ content instead of the decrease that would be expected since, to maintain positive cell pressure, the gas taken for the first sample had been replaced with cylinder $\mathrm{D}_{2}$ containing a lower level of ${ }^{4} \mathrm{He}(0.34 \mathrm{ppmV} / \mathrm{V})$. These findings support earlier observations that helium is released slowly from the palladium after an initial delay.

After making these measurements, an attempt was made to dislodge near surface ${ }^{4} \mathrm{He}$ either thermally 
or by $\mathrm{D}$ atom motion by subjecting the cathode to a period of compositional cycling, while still sealed in the calorimeter. Square and sine wave modulations of varying period and amplitude were imposed on the DC (negative) potential at the Pd electrode in an attempt to flux deuterium atoms through the interface and thus act to dislodge near-surface ad- or absorbed ${ }^{4} \mathrm{He}$ atoms. At the end of this period, the potential was reversed to withdraw all deuterium atoms from the Pd bulk. No excess heat was observed during the periods of oscillation although calorimetric uncertainties were large due to the strong departures from the steady state that accompanied the pulsing.

Gas samples were taken before this procedure, again after purging the cell and refilling with $\mathrm{D}_{2}$ from the gas bottle with $0.34 \mathrm{ppmV}{ }^{4} \mathrm{He}$, and once more after cycling. The latter sample exhibited the highest concentration of ${ }^{4} \mathrm{He}$ measured in this cell, specifically $2.077 \pm 0.01 \mathrm{ppmV} / \mathrm{V}$. By making a proper mass balance of the helium lost through sampling and purging, and that gained through make-up from the gas bottle, it is possible to assess with defined uncertainty the results of deuterium fluxing in freeing lightly trapped ${ }^{4} \mathrm{He}$. The final integral mass balance yielded a value of $104 \pm 10 \%$ of the expected value if the excess power in Figure 5 is due to a reaction of the sort $\mathrm{D}+\mathrm{D} \rightarrow{ }^{4} \mathrm{He}+\sim 23.8 \mathrm{MeV}$ (heat).

This value remains the most accurately determined in this field (in the sense that contributions from both the gas stream and the metal are included), but it suffers from the criticisms that the numbers of samples were few, and the largest value of ${ }^{4} \mathrm{He}$ measured was less than $50 \%$ of that in air. We note that ${ }^{4} \mathrm{He}$ has been produced numerous times in excess heat experiments at levels above that of the concentration in air. One example is shown in Figure 6. This plot illustrates the real-time correlation between excess heat and the growth of ${ }^{4} \mathrm{He}$ concentration in a metal-sealed, helium leak-tight vessel. The $Q$ value of $31 \pm 13$ and $32 \pm 13 \mathrm{MeV}$ per ${ }^{4} \mathrm{He}$ atom measured is also consistent with the reaction $\mathrm{D}+\mathrm{D} \rightarrow{ }^{4} \mathrm{He}+\sim 23.8 \mathrm{MeV}$ (heat). Because of the importance of this result, it is discussed further in Appendix B.

\section{EXCESS HEAT BEYOND THE BASIC FLEISCHMANN-PONS EXPERIMENT}

The importance of the basic Fleischmann-Pons experiment, as discussed in the previous section, is primarily scientific in the sense that the research provides strong evidence of a new excess heat effect of nuclear origin. In addition, this basic experiment has provided a focus for a significant research effort, and many important aspects of the experiment have been studied, as discussed above. During the past 15 years, numerous variants of this basic experiment have been proposed and executed. In what follows, we examine a subset of such studies.

\subsection{Self-Sustaining Excess Heat Effect}

Excess heat production in the absence of electrical input was first discussed by Fleischmann and Pons at ICCF $4 .^{74,75}$ It was found that cathodes continued to produce excess heat in some cases after the termination of the electrochemistry in which heat had been produced earlier during "normal" cell operation. This effect has been reported in other experiments, ${ }^{76,22,78,79}$ and is often referred to as "heat after death." These observations suggest a possible difference in the conditions required for the initiation of an excess heat effect as compared to the conditions required for sustaining the effect.

\subsection{Excess Heat in Other Metal Deuterides}

Excess heat in electrochemical experiments involving metal deuterides other than PdD has been reported in several modified Fleischmann-Pons experiments. Helium production in association with excess heat was studied in palladium alloys by Miles. ${ }^{80}$ Excess heat has been reported in TiD with a $\mathrm{D}_{2} \mathrm{O}-\mathrm{H}_{2} \mathrm{SO}_{4}$ electrolyte using thermal imaging. ${ }^{81}$ Excess heat and other effects were reported from an electrochemical 
cell with a Ti cathode by Bernardini and coworkers. ${ }^{76}$ Excess heat observations with Pt cathodes were reported by Dash ${ }^{52}$ and by Storms. ${ }^{82}$ Platinum does not form a deuteride, and the excess heat in this case is attributed to a surface layer. ${ }^{82}$

\subsection{Indirect Gas Loading}

Arata and Zhang introduced an interesting experiment in which palladium black is sealed within the interior of a palladium cathode, and the resulting composite (hollow) cathodes structure is electrolyzed. ${ }^{83}$ Deuterium gas within the interior of the cathode is in equilibrium with the deuterium in the highly loaded cathode, and the palladium black is loaded indirectly. Evidence for excess heat and helium production has been obtained from this kind of experiment. We discuss this further in Appendix C.

\section{NUCLEAR EMISSIONS}

The first report of emissions consistent with deuteron-deuteron fusion was made by Jones and coworkers in $1989,{ }^{2}$ who claimed that low-level neutrons near $2.45 \mathrm{MeV}$ were emitted from electrochemicallyloaded titanium deuteride. ${ }^{j}$ Since that time, there have been numerous reports of neutron and charged particle emission generally at low emission rates from metal deuterides, which are consistent with a deuteron-deuteron fusion reaction mechanism. In what follows, we will discuss some of this work. We note that there is in addition evidence in support of emissions that are clearly not associated with a deuteron-deuteron fusion reaction mechanism. A subset of these observations will be discussed below.

\subsection{The Jones Experiment}

Much effort has been devoted since 1989 to the Jones effect by Jones and coworkers, ${ }^{84,85}$ and also by other groups. ${ }^{32,33,86,87,88,89,90}$ Most of the effort has focused on neutron measurements, but there have been observations of charged particles as well. ${ }^{85}$ Low-level nuclear emissions typically occur in bursts lasting a few seconds to several days, ${ }^{84}$ and at lower current density than that discussed above in connection with the excess heat effect (Jones and coworkers reported neutron emission at $20 \mathrm{~mA} / \mathrm{cm}^{2}$ ). A distinct burst effect (see Figure 8) was reported by Wolf in neutron emission from PdD electrochemical experiments. ${ }^{91}$ This is reminiscent of a similar burst effect noted for the excess heat in the FleischmannPons experiment. It was noted in the early 1990s that there were considerable similarities between the electrochemical protocols and palladium cathodes used by Wolf in neutron emission experiments, and those used at SRI in excess heat experiments. In discussions between the two groups, it became apparent that the most significant difference between the two experiments was the current density involved. At SRI, excess heat was observed at elevated current densities, with a current threshold in the range of $200-300 \mathrm{~mA} / \mathrm{cm}^{2}$. At Texas A\&M, Wolf increased the current to about $30 \mathrm{~mA} / \mathrm{cm}^{2}$ to initiate neutron emission, but found no neutron emission at significantly higher current densities. ${ }^{92}$ The low-high current protocol of Takahashi discussed above scans through both regimes, and is associated with both excess heat and neutron emission. ${ }^{28}$.

\subsection{Stimulation of Nuclear Emissions with Electrical Current}

Cecil and coworkers reported charged particle emission in experiments where current was run through $\mathrm{TiD}_{x}$ [using $\mathrm{Ti}(662)$ alloy]. ${ }^{93}$ For example, a proton signal centered at $2.45 \mathrm{MeV}$ was presented. ${ }^{\mathrm{k}}$ Jones

${ }^{\mathrm{j}}$ Additionally present on the titanium surface were $\mathrm{Pd}, \mathrm{Cu}$, and $\mathrm{Li}$ due to deposition from the electrolyte.

${ }^{\mathrm{k}}$ The proton from the $\mathrm{d}(\mathrm{d}, \mathrm{p}) \mathrm{t}$ reaction initially has $3 \mathrm{MeV}$, and perhaps some energy degradation occurs if the proton is born inside the metal deuteride. 


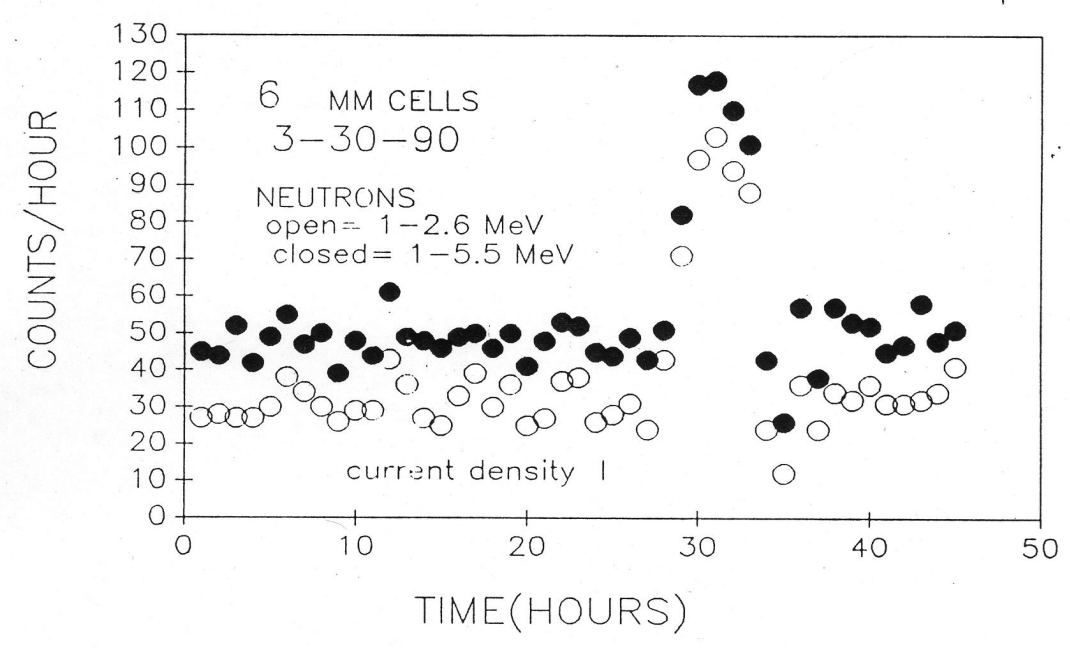

Figure 8. Neutron burst from PdD loaded electrolytically from the experiments of Wolf and coworkers.

and coworkers have recently used this same general approach. ${ }^{94,90}$ The group evacuated a heated chamber containing 25 to $250 \mu \mathrm{m}$ thick Ti foils, introduced 1 atmosphere of $\mathrm{D}_{2}$ gas and partially loaded the foils, which were then placed in front of a particle detector, or in a neutron counter. A low background nuclear detector system was used. Electrical current was run through the foils during nuclear counting. Background subtracted counts were observed for neutrons at typical rates of 40 counts per hour. Background subtracted counts were observed for charged particles identified as $<3 \mathrm{MeV}$ protons at typical rates of 100 counts per hour (and up to 2000 counts per hour), with emission rates varying strongly over the course of a few hour burst event. Results from a particularly strong burst are shown in Figure 9. The signal is centered at $2.4 \mathrm{MeV}$ and the particle identity is determined from a comparison with a similar spectrum obtained with a thin $\mathrm{Al}$ absorber foil. ${ }^{94}$ Background subtracted coincidences between two particles, consistent with protons and tritium from deuteron-deuteron fusion, occur at a rate of 1 count per hour in foils with no electrical current running. In this case, there is an additional experimental procedure of $\mathrm{LiOD}$ and $\mathrm{D}_{2} \mathrm{SO}_{4}$ surface treatment and rinsing prior to nuclear counting. In all cases in the recent Jones experiments, excess nuclear counts diminish with time, positive signals are observed greater than $50 \%$ of the time, and no excess nuclear counts are observed when $\mathrm{H}_{2}$ is substituted for $\mathrm{D}_{2}$.

\subsection{Neutrons from Ti Shards in Deuterium Gas}

Neutron emission consistent with $\mathrm{d}(\mathrm{d}, \mathrm{n})^{3} \mathrm{He}$ reactions were reported in 1989 from gas-loaded metal deuteride shards with thermal cycling. ${ }^{95}$ In these experiments the metal is loaded at high pressure and cycled between liquid nitrogen temperature and room temperature. Neutron emissions appear occasionally in burst epsisodes. ${ }^{96,97,98,99,100}$ High efficiency neutron detectors were employed, ${ }^{98}$ and some of the measurements were performed under conditions where the background was quite low. ${ }^{101,96}$ Research along these lines has not continued in recent years. The evidence in support of neutron emission from this kind of experiment is strong, but in such experiments the conditions are not well controlled. This, combined with a low associated emission frequency, made other approaches seem more attractive. ${ }^{96}$ 


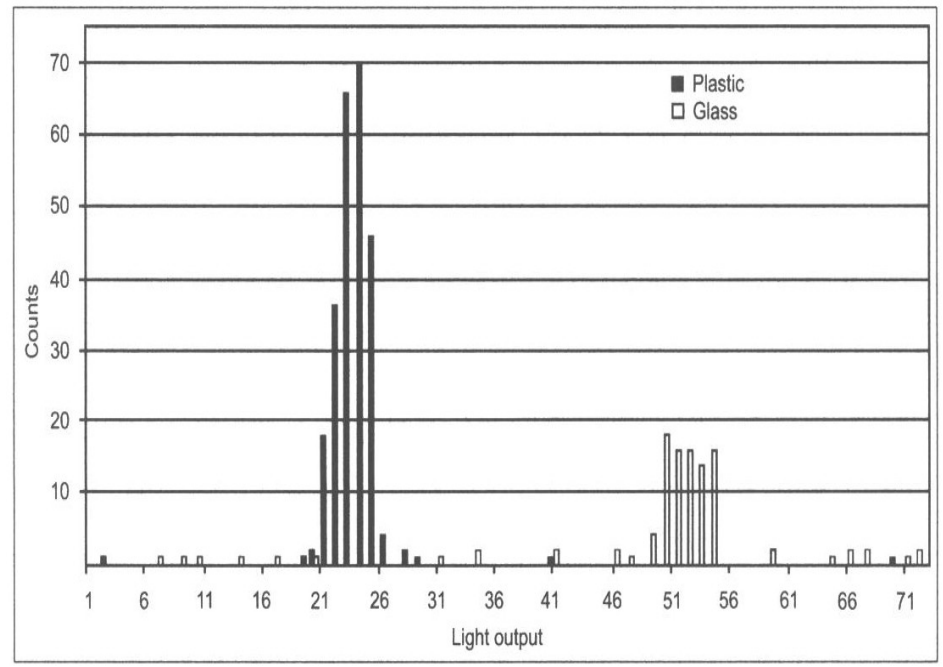

Figure 9. Proton spectrum near $2.4 \mathrm{MeV}$ from $\mathrm{TiD}_{x}$ taken over 21 minutes using a double scintillation detector, as presented by Jones at ICCF10. The two different signals are from two different scintillators (plastic and glass). The light output scale is related to the proton energy.

\subsection{Relation between Neutron Emission and Excess Heat Effect}

We note that the amount of energy associated with these low-level emissions is not observable calorimetrically. Whether there is a correlation between nuclear emission effects and excess heat or not has been under discussion since 1989. ${ }^{103}$ There have been several observations of excess heat with simultaneous diagnostics for neutron emission, and for x-ray and gamma emission. ${ }^{5,104,71}$ An anticorrelation between excess heat and neutrons was reported by Okamoto and coworkers. ${ }^{105}$ We have noted that excess heat production in the Fleischmann-Pons experiment has an associated current threshold around 200-300 $\mathrm{mA} / \mathrm{cm}^{2}$, while neutron emission is associated with lower current densities (around $30 \mathrm{~mA} / \mathrm{cm}^{2}$ in the experiments of Wolf, Jones, and coworkers cited above), suggesting that the different effects have different operating regimes. In experiments that operate with both high and low current densities, there are reports of both neutron emission and excess heat production. ${ }^{106,107}$ There is a study with the low-high current protocol in which a correlation is reported where cathodes producing the largest excess heat effect also show the largest neutron emission. ${ }^{108}$

\subsection{Nuclear Emissions not Attributable to Deuteron-Deuteron Fusion}

There are several reports for weak nuclear emissions which clearly are not associated with a deuterondeuteron fusion mechanism. In 1990, Cecil and coworkers noted the presence of very energetic charged particles from thin TiD foils up to and beyond $10 \mathrm{MeV}^{93}$ (see also the $\mathrm{PhD}$ thesis of $\mathrm{Liu}^{109}$ ). Energetic alphas around $15 \mathrm{MeV}$ have been observed by Lipson and coworkers from PdD. ${ }^{110}$ Both alphas and protons near $14 \mathrm{MeV}$ have been seen in experiments with TiD. ${ }^{111}$ The appearance of such signals under conditions that are similar to those associated with excess heat production and low-level deuterondeuteron fusion is significant, and provides additional information that may be helpful in understanding the underlying physical processes responsible for the new effects. 


\subsection{Broad Proton and Alpha Spectrum from Deuterons on TiD}

Kasagi and coworkers have reported anomalous results from beam experiments using $\operatorname{TiD}_{x}$ targets in which product nuclei are observed with a very large energy spread. ${ }^{112}$ This group bombarded $\mathrm{TiD}_{x}$ $(\mathrm{x}>1.2)$ foils with $90-150 \mathrm{keV}$ deuterons and observed protons with energies from 6-17 MeV and alphas with energies from 4.5-6.5 MeV at scattering angles between 135 and 155 degrees at a rate of $10^{-6}$ of the deuteron-deuteron fusion rate. An aluminium absorber foil in front of the particle detector stopped the elastically scattered beam. The energy spectra for the protons and alphas are consistent with a three-body reaction mechanism

$$
\mathrm{d}+\mathrm{d}+\mathrm{d} \rightarrow{ }^{4} \mathrm{He}+\mathrm{p}+\mathrm{n} \quad Q=21.62 \mathrm{MeV}(3 \text { body })
$$

Hubler and coworkers at the Naval Research Laboratory have partially confirmed the existence of this anomaly in that the protons have been observed in some, but not all, of the samples bombarded. A coincidence experiment between the proton and alpha would be required to confirm this reaction. The experiment is important, and thought by some to be related to other experiments that show anomalies in metal deuterides. It could be interpreted as a probe of the probability that two deuterons are close together in the solid when the bombarding deuteron encounters them. There is no viable conventional explanation for the existence of this nuclear signal.

\section{CONCLUSIONS}

The research discussed in this paper provides evidence for effects in three categories:

(1) The existence of a physical effect that produces heat in metal deuterides. The heat is measured in quantities greatly exceeding all known chemical processes and the results are many times in excess of determined errors using several kinds of apparatus. In addition, the observations have been reproduced, can be reproduced at will when the proper conditions are obtained, and show the same patterns of behavior. Furthermore, many of the reasons for failure to reproduce the heat effect have been discovered.

(2) The production of ${ }^{4} \mathrm{He}$ as an ash associated with this excess heat, in amounts commensurate with a reaction mechanism consistent with $\mathrm{D}+\mathrm{D} \rightarrow{ }^{4} \mathrm{He}+23.8 \mathrm{MeV}$ (heat).

(3) A physical effect that results in the emission of: (a) energetic particles consistent with $\mathrm{d}(\mathrm{d}, \mathrm{n})^{3} \mathrm{He}$ and $d(d, p) t$ fusion reactions, and (b) energetic alphas and protons with energies in excess of 10 $\mathrm{MeV}$, and other emissions not consistent with deuteron-deuteron reactions.

Experimental results for tritium production were noted, and anomalous results from deuteron beam experiments on $\operatorname{TiD}_{x}$ were discussed briefly. In each case, the effects cannot be accounted for by known nuclear or solid state physics. The underlying processes that produce these results are not manifestly evident from experiment. The scientific questions posed by these experiments are, in the opinion of the authors, both worthy and capable of resolution by a dedicated program of scientific research. 


\section{APPENDIX A: CALORIMETRIC ISSUES}

As enumerated by Storms, ${ }^{30}$ four questions must be addressed when evaluating the state of heat observations:

(1) Was the calorimetric technique used by Fleischmann and Pons sufficiently stable and accurate to see the claimed extra energy?

(2) Have others independently replicated the claims using stable and accurate calorimeters?

(3) Can prosaic sources of chemical energy or energy storage effects be ruled out?

(4) Have reasons for success or failure been discovered?

A clear, positive answer to the first question was available in massive detail ${ }^{114}$ but only retrospectively. Fleischmann and Pons used an open cell from which energy was lost in a variety of ways, including by infrared radiation, and as chemical energy carried with the evolving gases. The resulting differential equation was awkward and subject to misunderstanding. Fleischmann addressed the mathematical issues to the point where the isoperibolic method used can be seen to have accuracy better than 1\% (Fleischmann's estimate is $0.1 \%$ ). With daily automatic calibration, the Fleischmann and Pons calorimetric method was able to establish and assure stability for the length of time (months) needed to perform their experiments.

Because the cell was open to escaping gases, attention was also given to the possibility that an unknown and variable fraction of the evolving $\mathrm{D}_{2}$ and $\mathrm{O}_{2}$ gas may recombine to $\mathrm{D}_{2} \mathrm{O}$ within the calorimetric envelope. A reduction of this subtractive term would give rise to the appearance of "excess heat" when in reality it simply had a chemical origin. Quantification of the upper bound of this effect was made by Fleischmann and Pons, ${ }^{115}$ by Jones et al. ${ }^{116}$ and in final detail by Will. ${ }^{117}$ With 15 years of hindsight, it is now clear that the initial heat claims of Fleischmann and Pons must be taken at face value as quantitatively sound and capable of standing alone. Fortunately, this last is not necessary. Hundreds, possibly thousands, of attempts were made to replicate the Fleischmann and Pons effect. Apart from those conducted in 1989, when little was understood about necessary conditions, most researchers who attempted to reproduce the effect claimed success. We do not attempt to evaluate the bulk of these experiments or claims, although readers are invited to do so and could benefit in this regard by starting with the reviews by Storms. ${ }^{113}$

To address the second question above, we provide an example. Flow calorimetry with closed cells was selected at SRI at the outset in part to avoid ongoing criticisms of the Fleischmann and Pons (Fick's law) method. Electrochemical cells were operated thermodynamically closed, sealed, and immersed in the fluid flow. Rather than measuring heat flow as a temperature difference across a defined (and presumed stable) barrier, the emerging heat in the SRI experiments was measured as the temperature rise in a moving liquid mass that surrounded the cell. In this way, the governing equations become trivial: all considerations of heat source dependence and so-called "recombination" effects can be avoided in simple first principles operation. Where potential sources of error were anticipated or recognized, the calorimetric system was designed to yield conservative estimates. Over 50,000 hours of calorimetry to investigate the Fleischmann and Pons effect have been performed to date at SRI, most of it in calorimeters identical or very similar to that shown in Figure 10.

The object in Figure 10 is immersed in a constant temperature bath (typically held constant and uniform to within $3 \mathrm{mK}$ long term and short term). The bath is situated in a constant temperature room $( \pm 1 \mathrm{~K})$. Calorimetric fluid is drawn from the environing bath, past two inlet temperature sensors (100 $\Omega$ platinum resistance temperature sensor RTD's) through the flow labyrinth and past the cell under interrogation, which is encased in a brass fin structure for better and more uniform communication of heat. The fluid flow is then drawn upwards and constrained by the hemispherical top to flow through a 


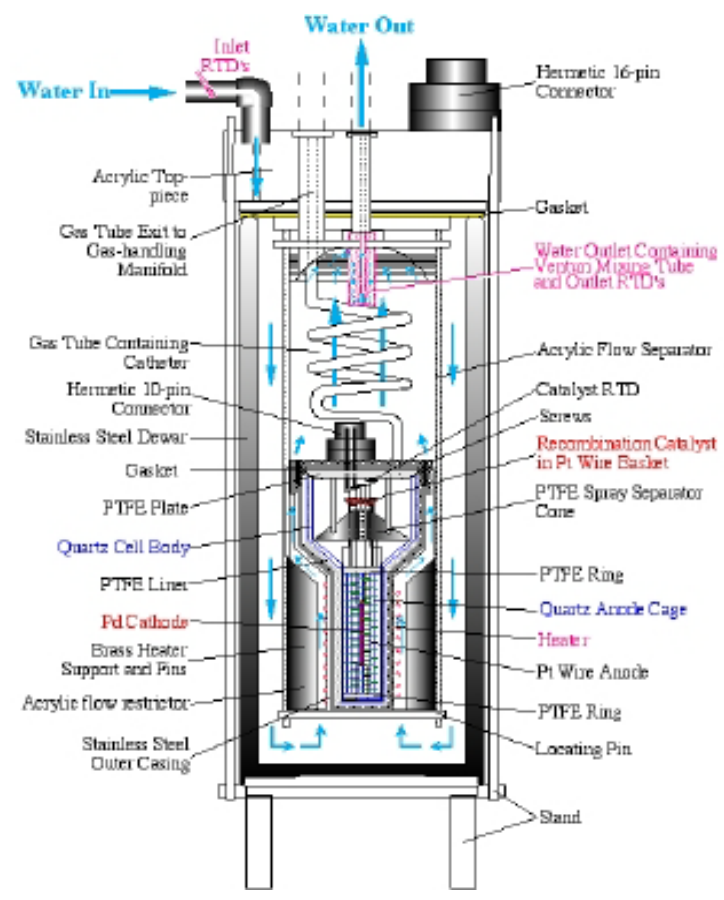

Figure 10. SRI mass flow calorimeter.

small hole and labyrinth, past and closely proximate to two outlet RTD's. Additional sensors of other types have been used to further assure accurate values of the measured temperature rise. The fluid is then drawn through a heat exchanger to the inlet of a constant volume displacement pump, and then delivered directly to an electronic balance. The balance is polled by computer to determine the fluid mass flow rate as $\Delta \mathrm{M} / \Delta \mathrm{t}$. In high power experiments requiring higher fluid flow rates, rotameter flow sensors were used in series with the mass flow measurement.

Calorimetry at SRI normally employed an electrical Joule heater either inside the cell or wound tightly on the cell circumference, constrained by the radial brass heat fins. This heater is used to calibrate the thermal efficiency of the convective heat flow process, and to allow for constant power operation in the presence of a variable electrochemical heat input. The equation of the calorimeter is thus:

$$
\begin{gathered}
P_{\text {in }}=(I V)_{\text {Electrochem }}+(I V)_{\text {Joule }}=\text { Constant } \\
P_{\text {out }}=\left(C_{p} \frac{\Delta M}{\Delta t}+k\right)\left(T_{\text {out }}-T_{\text {in }}\right) \\
P_{\text {xs }}=P_{\text {out }}-P_{\text {in }}
\end{gathered}
$$

In most experiments and all discussed here, the fluid was air-saturated $\mathrm{H}_{2} \mathrm{O}$ for which the heat capacity, $\mathrm{C}_{p}$, is well known. Current, voltage, and temperature sensors, and measurement instrumentation including the mass balance, were calibrated independently of the calorimeter. The only term requiring in-situ calibration is the conductive loss term $k$, which is the coefficient sum of all heat that leaves the calorimeter by means (primarily conductive) other than with the fluid flow. This term is small. By 
careful insulation, controlled geometry and selection of the fluid flow rate, $k$ was typically less than $1 \%$ of $C_{p}(\Delta M / \Delta t)$. Since $k$ is defined by geometry, it is also very unlikely to change and was observed to be stable.

Using these precautions the calorimetric method developed at SRI was shown by calculation and experiment ${ }^{27}$ to have an absolute accuracy between $\pm 0.35 \%$ and $0.5 \%$ depending on input conditions. It is worth noting that this accuracy is actually worse than that calculated by Fleischmann ${ }^{114}$ for the Fleischmann and Pons isoperibolic method when fully implemented. It is important to further note that the calorimetric methods are very different, the absolute accuracies comparable, and the results obtained consistent.

Several results have already been presented (Figures 1-5) to give a sense of the calorimeter signal-toerror ratio in heat-producing experiments. Below we summarize the findings and results from the major SRI effort to confirm (or refute) the existence of the Fleischmann and Pons effect.

(1) Sustained excess heat effects were observed from Pd electrodes undergoing electrolysis on more than 50 occasions with confidence more than three times the measurement uncertainty $(3 \sigma)$.

(2) Bursts or episodes of excess heat generation lasted from periods of several hours to more than a week.

(3) During a burst, the excess power was typically between 3 and $30 \%$ of the total electrical input power, with the largest sustained observation being in excess of $340 \%$.

(4) The intensity of this effect was in the range $3-300 \mathrm{~W} / \mathrm{cm}^{3}$.

(5) Sustained heat bursts exhibit an integrated energy at least ten times greater than the sum of all conceivable chemical reactions within the closed cell.

(6) When normalized to the number of cathode Pd (or D) atoms, the energy yield is of order 100-1000 $\mathrm{eV} /$ atom, with the largest observed yield $2076 \mathrm{eV} / \mathrm{Pd}$ atom.

(7) Endothermic effects were not observed. Calorimeters maintained a tight thermal balance at times when excess power was not being observed. During these intervals, calibration checks could be performed conveniently and reliably by adjusting the level of the complementary Joule heater to increase and decrease the system total input and output power. Except for the expected transient responses, the calorimeters were never observed to exhibit output heat power lower than input.

(8) Excess heat effects were observed to occur with $\mathrm{D}_{2} \mathrm{O}$ but not $\mathrm{H}_{2} \mathrm{O}$ electrolytes, under similar or more extreme conditions of loading, input power and current density.

(9) After an appreciable initiation or incubation time, heat generation appeared to be correlated to three variables: $\mathrm{D} / \mathrm{Pd}$ loading above a threshold; electrochemical current stimulus above a threshold; and deuterium flux or other dynamic stimulus.

With these results of a clear enthalpic excess unaccountable by known chemical or physico-chemical means, it was determined at SRI and elsewhere to undertake a thorough and systematic evaluation of possible nuclear processes, by careful screening of potential products. ${ }^{1}$ At SRI alone, serious efforts were made to interrogate active electrochemical and gas loading cells ${ }^{118}$ for neutrons, x-rays, $\gamma$-rays, charged particles, beta and other charge emission, tritium, ${ }^{3} \mathrm{He}$ and ${ }^{4} \mathrm{He}$. In over a decade of effort, evidence for all of these potential products was observed, except neutrons. Of the products observed, only ${ }^{3} \mathrm{H}$, ${ }^{3} \mathrm{He}$, and ${ }^{4} \mathrm{He}$ could in any way be correlated, quantitatively or temporally, with the enthalpy production rates.

\footnotetext{
${ }^{1}$ This is a matter of considerable importance and perhaps some confusion. Many claims for nuclear reaction products exist in the field now more broadly termed "low energy nuclear reactions" or LENR.
} 


\section{APPENDIX B: RESULTS FOR THE CASE EXPERIMENT AT SRI}

In 1998, Case reported results from an experimental technique that offered potential advantages over electrochemical Fleischmann and Pons experiments. ${ }^{54}$ He exposed commercial supported platinum group metal (PGM) hydrogenation catalyst materials to hydrogen or deuterium gas at slightly elevated pressure (1-3 atm) and temperature $\left(150-300^{\circ} \mathrm{C}\right)$ in sealed metal vessels.

In some cases, temperature sensed in a thermowell situated in the catalyst bed was higher by an amount sometimes exceeding $10^{\circ} \mathrm{C}$ under two different conditions: during heat bursts in $\mathrm{D}_{2}$; and in $\mathrm{D}_{2}$ relative to $\mathrm{H}_{2}$ at the same pressure. The difference in thermal conductivity between the gaseous isotopes does not appear to contribute appreciably to the observed temperature difference. The primary heat loss pathway does not significantly involve gas phase conduction. Furthermore, a temperature difference for the same heater power is observed only in unusual circumstances. Having surveyed a very extensive range of supported PGM catalysts, Case concluded that the effect:

(1) Could be observed with carbon supported catalysts but not with non-conductive supports

(2) Was exhibited with all PGM's (Pd, Pt, Ir and Rh) except Ru, which had not been well studied at the time of publication

(3) Occurred optimally in a narrow range of catalyst loading $(0.5-1 \%)$; at higher and lower loading the magnitude of the effect diminished and disappeared

(4) Occurs in a narrow range of temperature, about $130-300^{\circ} \mathrm{C}$, with activity peaking at $\sim 250^{\circ} \mathrm{C}$

(5) Was destroyed irreversibly when the catalyst was heated to temperatures much greater than $300^{\circ} \mathrm{C}$

Case concluded that his results represented evidence of a nuclear process because the energy production estimated from his calorimetry was much greater than could be accounted for from chemical processes. In addition, one post-test gas sample was reported to contain approximately $100 \mathrm{ppmV} / \mathrm{V}$ of ${ }^{4} \mathrm{He}$ in a 1 atm sample of $\mathrm{D}_{2}$.

The elements of simplicity, small materials inventory, rapid initiation, clear thermal signature and possible quantitative nuclear signature inspired many to attempt replication of what became known as the Case effect. Some succeeded in repeating the isotopic temperature disparity, although it quickly became clear that the experiment was far more demanding than it first seemed. ${ }^{\mathrm{m}}$

An effort was made at SRI to reproduce the Case experiment. Initial attempts to reproduce the effect with catalyst materials supplied by Case and in metal sealed vessels somewhat smaller than those employed by Case failed to observe systematic temperature differences between $\mathrm{H}_{2}$ and $\mathrm{D}_{2}$. Samples of gas withdrawn from $\mathrm{H}_{2}$ and $\mathrm{D}_{2}$ cells did not show an increase in ${ }^{4} \mathrm{He}$ when submitted to an on-line, high-resolution and high-sensitivity Extrel C-50 Quadrupole Mass Spectrometer. Two clear results of this first phase of activity were:

(1) The Case effect, whatever its cause, is not normally or always present in catalyst samples, even those certified by Case as being "active".

(2) ${ }^{4} \mathrm{He}$ is not a natural or normal component of these catalyst materials.

Significantly different results were obtained in a second campaign after a visit by Case to SRI to demonstrate his experimental procedures. Experiments were performed in pairs in nominally identical $50 \mathrm{cc}$ Nupro stainless steel sample flasks modified by the e-beam welded addition of a $1 / 8$ " stainless steel

${ }^{\mathrm{m}}$ One study by Clarke ${ }^{119}$ did not measure any significant increase in helium levels in a mass spectrometer where levels much smaller than $100 \mathrm{ppmV} / \mathrm{V}$ would have been easily recognized. Clarke, however, did not observe the procedures described by Case, ${ }^{54}$ which were in any case incomplete. Neither was Clarke able to measure any temperature effects and his geometry, which consisted of milligram single samples of "Case-type" catalyst confined with $\mathrm{D}_{2}$ or $\mathrm{H}_{2}$ in very small sealed $\mathrm{Pb}$ pipe sections, differed greatly from that used and recommended by Case. 


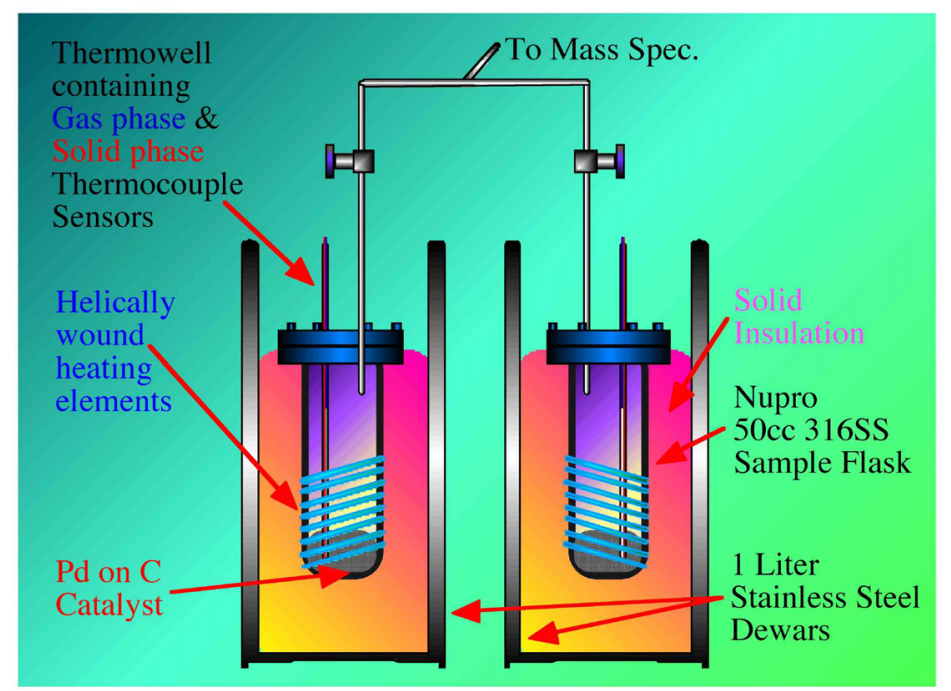

Figure 11. Configuration of the Case experiment at SRI.

thermowell and a 1-inch Cajon VCR fitting to permit admission of catalyst. $10 \mathrm{~g}$ samples of catalyst were loaded into the vessels, which were then mounted and supported as shown in Figure 11.

A heating element $1 \mathrm{~mm}$ diameter and $117 \mathrm{~cm}$ long was wound helically on the circumference of the bottom third of the cells and temperature was maintained by supplying power from a computer controlled DC supply. The two cells were mounted axially in 1-liter, $10 \mathrm{~cm}$ inside diameter stainless steel dewars, surrounded by granular insulation to maintain their geometry and impose a consistent thermal environment. A significant change in this second phase of activity was to expose just the top of the sample cells to ensure an axial heat flow; this was found to be important both for calorimetry and to recreate the Case effect. During the course of the experiment, the currents to and voltages across each heating element were monitored together with two thermocouples measuring temperatures in the thermowell of each cell, and an ambient temperature sensor. Typically experiments were operated in pairs, with one blank and one test cell, with the heater power set to keep the catalyst bed temperatures at nearly equal values. Test cells contained Case-certified $0.4-0.5 \% \mathrm{Pd}$ on $\mathrm{C}$ catalyst in $\mathrm{D}_{2}$. Blank cells contained samples of identical catalyst in $\mathrm{H}_{2}$ or inactivated or non-catalyst carbon in $\mathrm{D}_{2}$.

After hydrogen treatments and evacuation to clean the catalyst surfaces, cells were then subjected to an extended period "soak" in $\mathrm{H}_{2}$ to ensure by measurement that they were ${ }^{4} \mathrm{He}$ leak-tight and that any labile ${ }^{4} \mathrm{He}$ sources adsorbed or absorbed on the cell inner surface or catalyst volume had been exhausted. This period was also used to establish a reference temperature. Cells were then charged with $\mathrm{D}_{2}$ or recharged with $\mathrm{H}_{2}$ to the reference pressure, and their heat flow and helium levels monitored. Experiments exhibited a range of behaviors. Figure 12 summarizes 6 of 16 results of helium measurements in paired cells; these fall into three classes of behaviors:

(1) Cells that show no increase of ${ }^{4} \mathrm{He}$ over long periods of time (including all cells operated with $\mathrm{H}_{2}$ );

(2) Cells that exhibit a slow, approximately exponential increase in $\left[{ }^{4} \mathrm{He}\right]$ with time, following a trajectory very different from that expected for convective or diffusional leakage in from the ambient;

(3) Cells that display no measurable increase in $\left[{ }^{4} \mathrm{He}\right]$ for a period of several days, followed by a rapid, approximately linear rise in $\left[{ }^{4} \mathrm{He}\right]$ to levels sometimes exceeding that of the ambient background. 


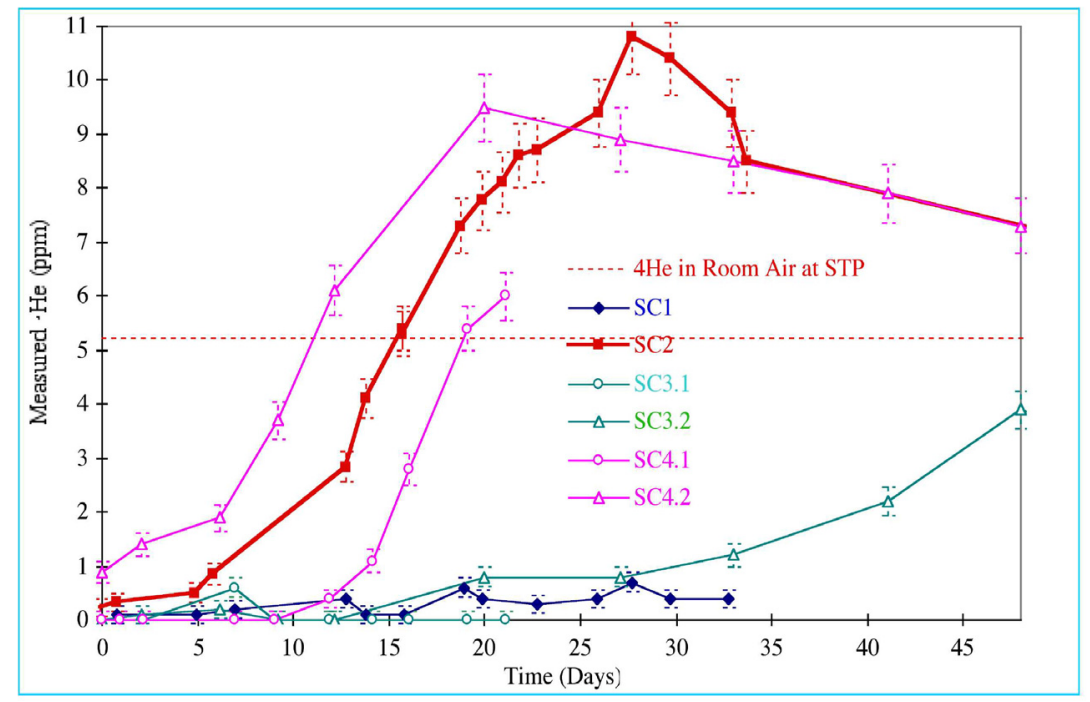

Figure 12. Results of ${ }^{4} \mathrm{He}$ measurements from the Case experiment at SRI.

Using data from temperature sensors situated in the catalyst and gas phases it was possible to make heat flow estimates in one of two ways:

(1) Gradient method, based on the relationship between the temperature difference between the catalyst bed and confined gas, and the heater input power;

(2) Differential method, based on the temperature differences between active and the reference catalyst bed sensors and room temperature, as a function of the relative input heater powers.

The energy estimated in excess of that provided by the heater for these two calorimetric methods is plotted in Figure 13, together with the measured helium concentration during the time of greatest derivative, $\partial\left[{ }^{4} \mathrm{He}\right] / \partial t$ in experiment $\mathrm{SC} 2$. Excess heat and the apparent increase in $\left[{ }^{4} \mathrm{He}\right]$ seem to be temporally correlated.

In an attempt to establish a quantitative correlation, Figure 6 plots the two calorimetric estimates of excess heat production interpolated from Figure 13, versus the measured increase in $\left[{ }^{4} \mathrm{He}\right]$ (the value plotted in Figure 13 minus the ${ }^{4} \mathrm{He}$ initially present in the $\mathrm{D}_{2}$ gas). Regression lines through these data incorporating the origin have slopes: $Q=31 \pm 13$ and $32 \pm 13 \mathrm{MeV}$ per ${ }^{4} \mathrm{He}$ atom, respectively, for the gradient and differential calorimetric methods. The $Q$ value of $\sim 23.8 \mathrm{MeV}$ expected for reaction mechanisms consistent with $\mathrm{D}+\mathrm{D} \rightarrow{ }^{4} \mathrm{He}$ falls with the assigned uncertainties. The apparent shortfall of ${ }^{4} \mathrm{He}$ may occur for the same reasons observed in electrolytic Fleischmann and Pons studies discussed in Sections 3.1 and 3.2. In that case the residual helium putatively formed in a new nuclear process is released from the metal only slowly to the gas phase for analysis.

Another factor must also be considered in accounting for the ${ }^{4} \mathrm{He}$ mass balance. In Figure 12 for experiments SC2 and SC4.2 ( $\mathrm{D}_{2}$ on United Catalysts G75D and E, corresponding to $0.4 \%$ and $0.5 \% \mathrm{Pd}$ on $\mathrm{C}$, respectively), the final trajectories of ${ }^{4} \mathrm{He}$ with time show essentially the same linear decreasing trend. It is apparent the ${ }^{4} \mathrm{He}$ is either leaving the cell, in which case it may enter if the partial pressure of ${ }^{4} \mathrm{He}$ is lower inside than the ambient $5.22 \mathrm{ppmV} / \mathrm{V}$, or else ${ }^{4} \mathrm{He}$ is being adsorbed or absorbed onto or into the stainless steel or catalyst solid components, in which case these must be considered as potential sources of the observed increase.

The first is unlikely since the cells were demonstrated repeatedly to be helium leak-tight. An experiment performed to test the second hypothesis demonstrated clearly that ${ }^{4} \mathrm{He}$ adsorbs or absorbs into 


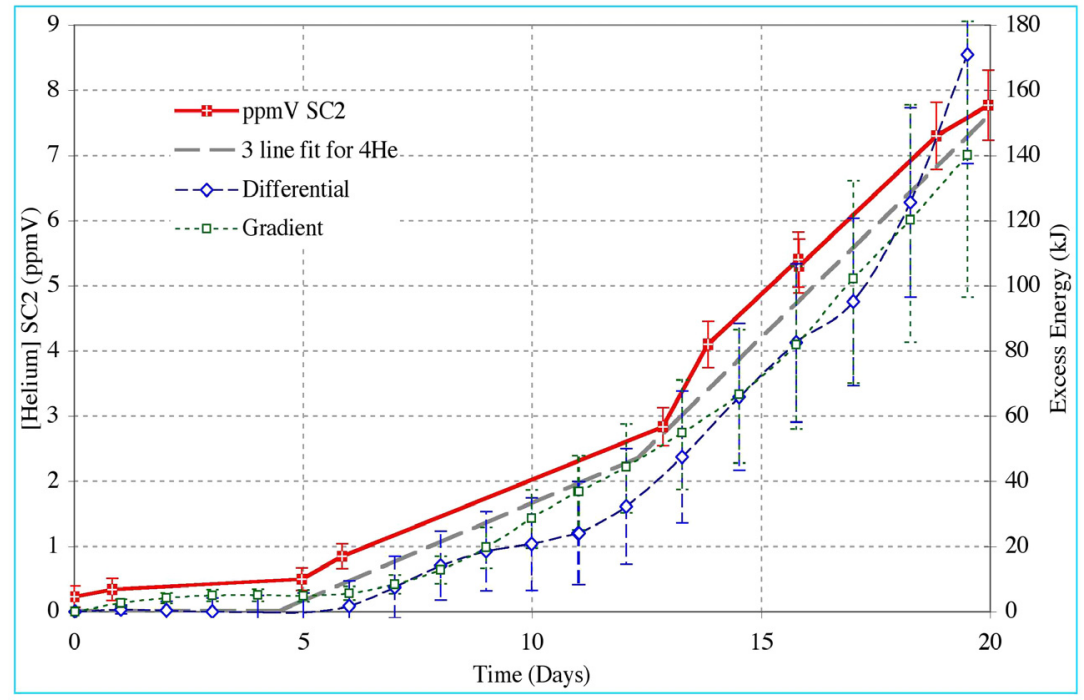

Figure 13. Excess energy and helium production as a function of time from the Case experiment at SRI.

this class of catalyst material and also into or onto activated charcoal of similar geometry, with a rate consistent with the declining trend in Figure 12, at similarly elevated temperatures. There is reasonable confidence that the ${ }^{4} \mathrm{He}$ source of the rising trends in Figures 12 and 13 is not a release of stored ${ }^{4} \mathrm{He}$ from the catalyst for the following reasons:

(1) A helium storage mechanism is expected to be reversible. A rate such as that shown in Figure 12 should manifest itself clearly in the 5 day hydrogen pre-soak intended to address this concern (among others) before experiment initiation.

(2) The rate of helium sequestration in carbon and carbon catalyst materials, at room temperatures, appears to be negligible.

(3) Multiple random samples of catalyst were subjected to direct assay for ${ }^{4} \mathrm{He}$ by heating to temperatures in excess of $2250 \mathrm{~K}$ in the mass spectrometers of Clarke ${ }^{120}$ and Arata and Zhang. In all cases these experiments demonstrated that the volume of ${ }^{4} \mathrm{He}$ contained with $\mathrm{Pd}$ on $\mathrm{C}$ catalyst materials was less than that in an equivalent volume of air.

We conclude, tentatively, that helium is produced in a process that involves deuterium, but not hydrogen, which evolves heat commensurate with a nuclear mechanism consistent with a $\mathrm{D}+\mathrm{D} \rightarrow{ }^{4} \mathrm{He}$ reaction. Even taking account of the rate of helium re-ad/absorption, the mean value of the ${ }^{4} \mathrm{He}$ falls below that expected (assuming $23.8 \mathrm{MeV}$ reaction energy) from the measured heat evolution. These observations regarding released ${ }^{4} \mathrm{He}$ are consistent with those made in studying electrolytic Fleischmann and Pons cells. Calculating the excess power density normalized to the volume of Pd for Cell SC2, we obtain a maximum value of $\sim 50 \mathrm{~W} \mathrm{~cm}{ }^{-3}$, also consistent with the values observed in electrolytic loading of $\mathrm{Pd}$. Further attempts to replicate the Case effect and the above-described results are underway at ENEA Frascati. 


\section{APPENDIX C: THE ARATA AND ZHANG EFFORT}

Arata and Zhang have been major contributors to the research area under discussion. Dr. Arata came from the plasma fusion community. He and his colleague Dr. Yue-Chang Zhang began working as a team on cold fusion in about 1989. Their researches have been carried out in cooperation with other material scientists, including H. Fujita, who gave the Honda Memorial Lecture on atom clusters in 1994.

In the early 1990s their researches led them to develop the DS (Double Structure) cathode, which is a Pd bottle whose "outer structure" is the wall of a Pd bottle and whose "inner structure" is filled with Pd-black. In 1994, they published observations of excess heat using open-cell DS-cathodes ${ }^{83}$ and water-flow Dewar calorimetry similar to that described in Appendix A. In a continuous 3-month run Arata and Zhang observed excess heat power averaging about 15 Watts. Data from another run shows a heat balance for about 11 days, followed by 12 days with excess heat power averaging $\sim 80 \mathrm{~W}$, with the output heat $\sim 1.8$ times input energy. An initiation time with no excess heat effect was seen in these, and in all other experiments with DS cathodes. Two additional 100-day runs exhibiting continuous excess heat of about $10 \mathrm{~W}$ were published in $1995 .{ }^{121}$ Three additional runs showing $\sim 10-20 \mathrm{~W}$ excess heat were published in 1996. ${ }^{122,123}$ One of these runs continuously produced excess heat for 6 months. In another run, a mechanical pressure gauge was fitted to the DS cathode and measured the gas pressure inside the Pd bottle. During much of the run, the pressure gauge pinned at 800 bar. Excess heat power was much reduced when the pressure was less than 200 bar. Excess heat studies continued through 2002. An especially important result is presented in a more recent publication. ${ }^{124}$ In this run, the inner cathode consisted of metal powder derived from an oxidized $\mathrm{Zr}_{65} \mathrm{Pd}_{35}$ alloy, showing that powders other than Pd-black can produce excess heat. In 1998, a pair of DS cathodes were run in series, with one DS cathode in $\mathrm{D}_{2} \mathrm{O}$ electrolyte and the other in $\mathrm{H}_{2} \mathrm{O}$ electrolyte. The DS cathode in $\mathrm{D}_{2} \mathrm{O}$ electrolyte showed excess heat rising to $20 \mathrm{~W}$, while the one in $\mathrm{H}_{2} \mathrm{O}$ electrolyte showed no excess heat. ${ }^{125}$

\section{Replication Effort at SRI}

A pair of DS cathodes prepared by Arata and Zhang were operated at SRI under conditions closely similar to those employed in Japan. Two nominally identical cells were exercised cathodically within intentionally similar cells, one in $0.3 \mathrm{M} \mathrm{LiOD}$ and the other in $0.3 \mathrm{M} \mathrm{LiOH}$. Calorimetric accuracy was less than that normally present in the SRI Mass Flow Calorimeters because of the need to operate at very high input power levels to exceed the threshold current density on large area cathodes. It was also not possible to submerge the Arata-Zhang cell completely in the constant temperature bath. Nevertheless, the results obtained at SRI ${ }^{118}$ confirm the excess heat results published earlier by Arata and Zhang. In the same range of input powers, the heavy water cell clearly yielded more output heat than the light water cell when operated simultaneously and monitored with the same instruments. The maximum excess power observed in $\mathrm{D}_{2} \mathrm{O}$ was $9.9 \pm 1.3 \%$ of the measured power input, with the average value being approximately half the maximum. The measured excess power exceeded the experimental uncertainty (1-2\% depending on conditions) for a period of $\sim 86$ days to produce an integrated energy excess of $64 \pm 6 \mathrm{MJ}$ for the $\mathrm{D}_{2} \mathrm{O}$ cell. For the $\mathrm{H}_{2} \mathrm{O}$ cell in the same period of time, the measured energy excess was $-1 \pm 6$ MJ.

At the conclusion of the experiment, both cathodes were removed and placed successively in a sealed chamber where they were punctured mechanically, and the gas contents of the cathode void volumes extracted for analysis. The Pd black powders also were removed and the Pd metal walls of the hollow

cathodes were sectioned for ${ }^{3} \mathrm{He}$ and ${ }^{4} \mathrm{He}$ analysis. Significant amounts of tritium and ${ }^{3} \mathrm{He}$ (from the decay of tritium) were found inside the interior of the DS cathode electrolyzed in heavy water. Small amounts of ${ }^{4} \mathrm{He}$ were attributed to atmospheric contamination. Detailed results and conclusions from this work ${ }^{126}$ and the results of later analyses are summarized here: 


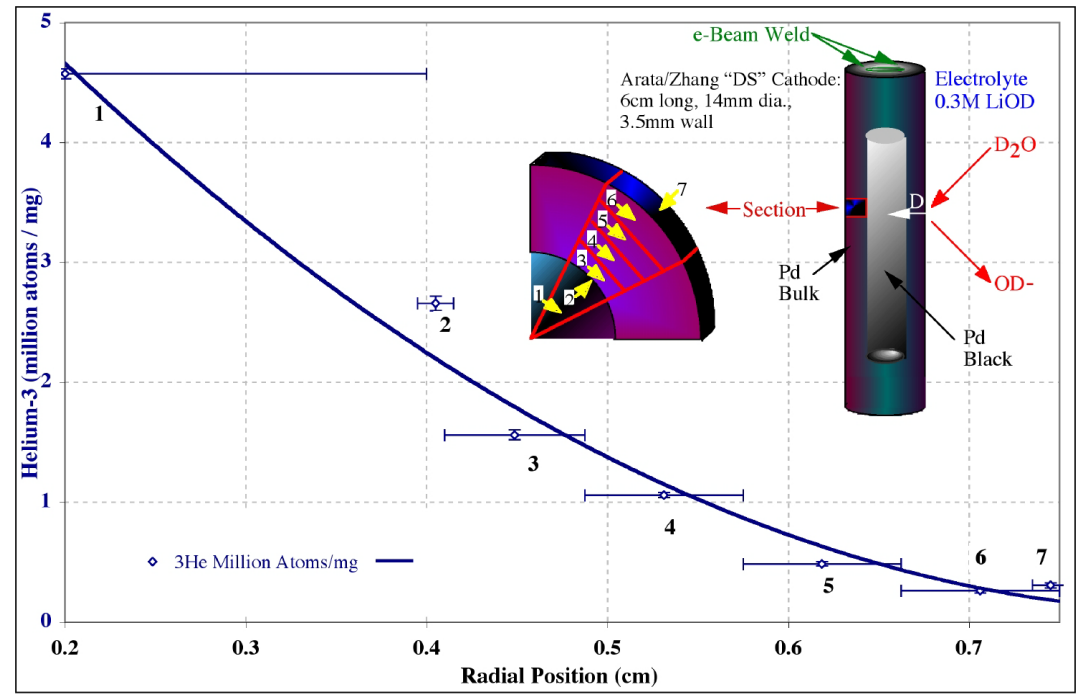

Figure 14. The ${ }^{3} \mathrm{He}$ profile as a function of radius observed in an Arata-type, double structured cathode experiment at SRI.

(1) Production of tritium was between 2 and $5 \times 10^{15}$ atoms.

(2) Assuming that the ${ }^{3} \mathrm{He}$ is from tritium decay, independent determinations of both quantities allows for a determination of when the tritium was generated. Modeled as a single event, the generation of tritium computed from the measured yields occurred during the period of cathodic electrolysis.

(3) There is definite evidence of excess ${ }^{3} \mathrm{He}$ from tritium decay in all samples of gas, $\mathrm{Pd}$ bulk metal and $\mathrm{Pd}$ black from the $\mathrm{D}_{2} \mathrm{O}$ experiment.

(4) Samples of $\mathrm{Pd}$ taken from a similar and contemporaneous electrode run with $\mathrm{H}_{2} \mathrm{O}$ show low ${ }^{3} \mathrm{He}$ levels consistent with blank $\mathrm{Pd}$.

(5) Measurements of the ${ }^{3} \mathrm{He}$ gradient through the $3.5 \mathrm{~mm}$ wall of the $\mathrm{D}_{2} \mathrm{O}$ cathode show that the ${ }^{3} \mathrm{He}$ is the decay product of tritium, which diffused from a source inside the electrode void volume (see Figure 14).

(6) $\mathrm{A} \sim 30 \%$ increase in tritium levels in the $\mathrm{D}_{2} \mathrm{O}$ electrolyte measured by liquid scintillation methods is quantitatively consistent with the integral flux of tritium departing the cathode void and registered in the cathode walls.

(7) The total inventory of tritium in the initial electrolyte and its increase, while substantial, represents only $0.05 \%$ of the total tritium mass balance following the experiment.

(8) No evidence was found for ${ }^{4} \mathrm{He}$ in the interior gas (in the hollow within the cathode) or in the metal, that was quantitatively consistent with the measured excess heat.

The results of gas, metal and electrolyte phase ${ }^{3} \mathrm{He}$ and tritium analyses compel the conclusion that tritium was sourced in, on or adjacent to the $\mathrm{Pd}$ black in the void of the $\mathrm{D}_{2} \mathrm{O}$ double-structure cathode. While neither sought nor expected, this result provides sufficient evidence of the formation of a wholly nuclear product in an essentially electrochemical experiment to merit further study. Of concern, however, is the apparent absence of ${ }^{4} \mathrm{He}$.

\section{Excess Heat and Helium}

Having convinced themselves that non-chemical heat production within DS cathodes is a real phenomenon, Arata and Zhang sought to identify helium nuclear products using quadrupole mass spectroscopy. They constructed a welded stainless steel manifold vacuum system evacuated with clean turbo 
pumps. They also built a small furnace system for outgassing metal powder test samples, and later developed a protocol using a Ti getter pump for removing chemically reactive gases from test volumes of desorbed gas. The manifold system included two dedicated mass spectrometers: one normally used to repeatedly scan the mass-4 peak structure, and the other to repeatedly scan the mass-3 peak structure. The initial analysis program was restricted to a study of desorbed gases from furnace-heated, as-received and post-run Pd-black. The quadrupole instruments were very clean and had moderate mass resolution. Arata and Zhang routinely observed the ${ }^{4} \mathrm{He}^{+}$peak resolved from the $\mathrm{D}_{2}^{+}$peak. ${ }^{123}$ The gas desorption studies ${ }^{127}$ provided compositional analysis of both strongly bound gases (released at $\mathrm{T}>1000^{\circ} \mathrm{C}$ ) and less strongly bound gases (released at $\mathrm{T}<800^{\circ} \mathrm{C}$ ). They repeatedly demonstrated that post-run $\mathrm{Pd}$ powder always showed easily measurable ${ }^{4} \mathrm{He}^{+}$peaks, whereas as-received $\mathrm{Pd}$ powder showed no detectable ${ }^{4} \mathrm{He}^{+}$peaks. In 1998, they detected ${ }^{3} \mathrm{He}^{+}$within a resolved mass-3 peak structure. They found that they could often measure ${ }^{3} \mathrm{He}$ even when the mass-3 peak was not resolved. The ${ }^{3} \mathrm{He}^{+}$fraction could be distinguished from the $\mathrm{HD}^{+}$fraction by measuring the peak height as a function of ion source voltage. ${ }^{128}$ The helium signal always made its appearance at a higher voltage due to its higher ionization potential. In 1999, following the experiment at $\mathrm{SRI}^{118}$ and post-test sampling ${ }^{126}$ described above, Arata and Zhang expanded their studies to include analysis of intergranular and ullage gas from the interior volume of one of their DS cathodes. They added an aliquot sampling volume to their manifold and built an assembly for piercing the DS cathode and for collecting gas samples. They used their system to collect both prompt release gas samples from the room temperature DS-cathode and slow release gas samples from the moderately heated DS-cathode. The helium signals were strong and clean. Measurements corresponded to a total ${ }^{4} \mathrm{He}$ production $\sim 0.05 \%$ of that required to explain the run-integrated excess heat measured for the test cathode. ${ }^{129}$

Whether $0.05 \%$ as observed in Osaka or $0.00 \%$ observed in similar experiments performed at SRI, the discrepancy relative to the integrated excess heat is large, and this difference has not been resolved. Possible explanations are:

(1) The measurement of heat in both laboratories was substantially in error and no ${ }^{4}$ He should be expected. The heat associated with the generation of tritium (measured as ${ }^{3} \mathrm{He}$ by Arata and Zhang) would be unmeasurable in either calorimeter.

(2) Heat was produced in the cathode void by nuclear reaction of $D$, but the bulk of product helium was lost before sample collection due to micro-fractures, which occur in surface-stressed Pd, as described by A. Farkas. ${ }^{130}$

(3) Heat was produced as in Fleischmann and Pons electrolytic cells at the cathode outer surface where loading, deuterium chemical potential, and stimulation are the greatest. The helium produced was only tenuously attached to the Pd surface and vented to the atmosphere in the Arata Zhang electrolytic cells, which are helium permeable. ${ }^{\mathrm{n}}$ In this case, one must ascribe a secondary, not primary purpose for the cathode void and its enclosed Pd black, which conflicts with the hypothesis of Arata and Zhang.

This is an important question that will be resolved as a result of continued experimentation underway at Osaka University, SRI, and ENEA Frascati.

\footnotetext{
${ }^{\mathrm{n}}$ In other words, helium from the outer surface is not collected and measured in these experiments.
} 


\section{REFERENCES}

1. M. Fleischmann, S. Pons and M. Hawkins, J. Electroanal Chem., 201, p.301 (1989); Errata, 263 p. 187 (1990). See also M. Fleischmann, S. Pons, M.W. Anderson, L.J. Li and M. Hawkins, J. Electroanal. Chem., 287, p. 293 (1990).

2. S.E. Jones, E.P. Palmer, J.B. Czirr, D.L. Decker, G.L. Jensen, J.M. Thorne, S.F. Taylor and J. Rafelski, "Observation of cold nuclear fusion in condensed matter," Nature 338737 (1989).

3. E. Storms, "Calorimetry 101 for cold fusion: methods, problems and errors," http://www.lenrcanr.org/acrobat/StormsEcalorimetr.pdf

4. S. Pons and M. Fleischmann, Proc. ICCF1, p. 1 (1990).

5. D. Gozzi, P. L. Cignini, M. Tomellini, S. Frullani, F. Garibaldi, F. Ghio, M. Jodice and G. M. Urciuoli, Proc. ICCF2, p. 21 (1991).

6. M. C. H. McKubre, R. Rocha-Filho, S. I. Smedley, F. L. Tanzella, S. Crouch-Baker, T. O. Passell, and J. Santucci, Proc. ICCF2, p. 419 (1991).

7. D. Macdonald, M.C.H. McKubre, A. C. Scott and P. R. Wentrcek, I E EC Fundamentals, 20, p. 290, (1981).

8. M.C.H. McKubre, R.C. Rocha-Filho, S. I. Smedley and F. L. Tanzella, "Calorimetry and electrochemistry in the D/Pd System", Proc. ICCF1, p. 20 (1990).

9. K. Kunimatsu, N. Hasegawa, A. Kabota, N. Imai, N. Ishikawa, H. Akita and Y. Tsuchida, "Deuterium loading ratio and excess heat generation during electrolysis of heavy water by a palladium cathode in a closed cell using a partially immersed fuel cell anode," Proc. ICCF3, p. 31 (1992).

10. N. Hasegawa, N. Hayakawa, Y. Tsuchida, Y. Yamamoto, and K. Kunimatsu, Proc. ICCF4, Vol. 1, p. 3-1 (1993).

11. M. C. H. McKubre and F. Tanzella, Proc. ICCFr, p. 230 (1998).

12. L. Bertalot, L. Bettinali, F. DeMarco, V. Violante, P. De Logu, T. Dikonimos Makris and A. La Barbera, Proc. ICCF2, p. 3 (1991).

13. S.E. Koonin and M. Nauenberg, "Cold fusion in isotopic hydrogen molecules," Nature 339, 690 (1989).

14. J. O'M. Bockris and A. K. N. Reddy, Modern electrochemistry; an introduction to an interdisciplinary area, New York, Plenum Press (1970).

15. S. Pons, M. Fleischmann, C. T. Walling, J. P. Simons, International PCT Patent Application PCT/US90/01328, International Patent number WO 90/10935 (1990).

16. L. Bertalot, A. DeNinno, F. DeMarco, A. La Barber, F. Scaramuzzi, V. Violante, "Excess power production in electrolysis experiments and ENEA Frascati," Proc. ICCF5, p. 34 (1995).

17. E. Storms, Proc. ICCF6, p. 105 (1996).

18. E. Storms, "Relationship between open-circuit-voltage and heat production in a Pons-Fleischmann cell," Proc. ICCF\%, p. 356 (1998).

19. M. Swartz and G. Verner, "Excess heat from low-electrical conductivity heavy water spiral-wound $\mathrm{Pd} / \mathrm{D}_{2} \mathrm{O} / \mathrm{Pt}$ and $\mathrm{Pd} / \mathrm{D}_{2} \mathrm{O}-\mathrm{PdCl}{ }_{2} / \mathrm{Pt}$ Devices," Proc. ICCF10, (2004).

20. S. Pons and M. Fleischmann, Proc. ICCF2, p. 349 (1991).

21. M. Fleischmann, Proc. ICCF5, p. 152 (1995).

22. M. H. Miles, S. Szpak, P. A. Mosier-Boss, and M. Fleischmann, Proc. ICCF9, p. 250 (2002).

23. Proc. ICCF4, Vol. 2, p. 18-1 (1993).

24. E. Storms, "Some characteristics of heat production using the "cold fusion" effect," Proc. ICCF4, Vol. 2, p. $4-1$ (1993).

25. L. Case, in his oral presentation at ICCF10.

26. M.C.H. McKubre, S. Crouch-Baker, A. M. Riley, S. I. Smedley and F. L. Tanzella, "Excess power observations in electrochemical studies of the D/Pd system; the influence of loading" Proc. ICCF3, p. 5 (1992).

27. M. C. H. McKubre, S. Crouch-Baker, F. L. Tanzella, S. I. Smedley, M. Williams, S. Wing, M. Maly-Schreiber, R. C. Rocha-Filho, P. C. Searson, J. G. Pronko, and D. A. Koehler, Development of Advanced Concepts for Nuclear Processes in Deuterated Metals, EPRI Report TR-104195, August 1994.

28. A. Takahashi, A. Mega, T. Takeuchi, H. Miyamura, and T. Iida, Proc. ICCF3, p. 79 (1992).

29. T. Aoki, Y. Kurata, E. Ebihara, N. Yoshikawa, Proc. ICCF4, Vol. 2, p. 23-1 (1993).

30. E. K. Storms, "A study of those properties of palladium that influence excess energy production by the "Pons-Fleischmann" effect", (1996) http://www.lenr-canr.org/acrobat/StormsEastudyofth.pdf

31. F. De Marco, A. De Ninno, A. Frattolillo, A. La Barbera, F. Scaramuzzi, and V. Violante, Proc. ICCF6, p. 145 (1996). 
32. A. Takahashi, T. Takeuchi, T. Iida, and M. Watanbe, "Neutron spectra from $\mathrm{D}_{2} \mathrm{O}-\mathrm{Pd}$ cells with pulse electrolysis," Proc. Provo meeting, p. 323 (1990).

33. A. Takahashi, T. Iida, T. Takeuchi, A. Mega, S. Yoshida and M. Watanabe, "Neutron spectra anc controllability by PdD/Electrolysis cell with low-high current pulse operation," Proc. ICCF2, p. 93 (1991).

34. J. O'M Bockris, D. Hodko, and Z. Minevski, "The mechanism of deuterium evolution on palladium: Relation to heat bursts provoked by fluxing deuterium across the interface," Proc. ICCF2, p. 337 (1991).

35. E. Yamaguchi, and T. Nishioka, "Direct evidence for nuclear fusion reactions in deuterated palladium," Proc. ICCF3, p. 179 (1992).

36. H. Sugiura and E. Yamaguchi, Proc. ICCF\%, p. 366 (1998).

37. E. Yamaguchi and H. Sugiura, Proc. ICCF\%, p. 420 (1998).

38. C. Bartolomeo, M. Fleischmann, G. Larramona, S. Pons, J. Roulette, H. Sugiura, and G. Preparata, "Alfred Coehn and after: The $\alpha, \beta, \gamma$ of the palladium-hydrogen system," Proc. ICCF4, Vol. 1, p. 19-1 (1993).

39. F. Celani, A. Spallone, P. Tripodi, A. Petrocchi, D. DiGioacchino, P. Marini, V. DiStefano, S. Pace, and A. Mancini, Proc. ICCF5, p. 57 (1995).

40. F. Celani, A. Spallone, P. Tripodi, D. DiGioacchino, P. Maini, V. DiStefan, A. Mancini, and S. Pace, Proc. ICCF6, p. 93 (1996).

41. G. Preparata, Proc. ICCF6, p. 136 (1996).

42. M.C.H. McKubre, S. Crouch-Baker, A.K. Hauser, S.I. Smedley, F.L. Tanzella, M.S. Williams, and S.S. Wing, "Concerning reproducibility of excess power production", Proc. ICCF5, p. 17 (1995).

43. J. Tian, X. Z. Li, W. Z. Yu, D. X. Cao, R. Zhou, Z. W. Yu, Z. F. Jiang, Y. Liu, J. T. He, and R. X. Zhou, "Anomalous heat flow and its correlation with deuterium flux in a gas-loading deuterium-palladium system, Proc. ICCF9, p. 353 (2002).

44. J. O'M Bockris, et al., Proc. ICCF4, Vol. 2, p. 1-1 (1993).

45. X. Z. Li, B. Liu, N. N. Cai, Q. M. Wei, J. Tian, and D. X. Cao, Proc. ICCF10, (2004).

46. Y. Iwamura, M. Sakano, and T. Itoh, Jpn. J. Appl. Phys. 414642 (2002).

47. Y. Iwamura, T. Itoh, M. Sakano, S. Sakai, and S. Kuribayashi, "Low energy nuclear transmutation in condensed matter induced by $\mathrm{D}_{2}$ gas permeation through Pd complexes: Correlation between deuterium flux and nuclear products," Proc. ICCF10, (2004).

48. D. Letts and D. Cravens, "Laser stimulation of deuterated palladium: Past and present," Proc. ICCF10, (2004).

49. D. Cravens and D. Letts, "Practical techniques in CF research: Triggering methods," Proc. ICCF10, (2004).

50. T. O. Passell, Proc. ICCF5, p. 603 (1995).

51. T. O. Passell, Proc. ICCF9, p. 299 (2002).

52. J. Dash, Proc. ICCF6, p. 477 (1996).

53. T. Bressani, "Nuclear products in cold fusion experiments, comments and remarks after ICCF-6," Proc. ICCF6, p. 703 (1996).

54. L. C. Case, "Catalytic fusion of deuterium into helium-4", Proc. ICCF7, p. 48 (1998).

55. M. H. Miles and B. Bush, "Search for anomalous effects during $\mathrm{D}_{2} \mathrm{O}$ Electrolysis Using Palladium Cathodes", Proc. ICCF3, p. 189 (1992). See also: M. H. Miles, B. Bush, and J. J. Lagowski, "Anomalous effects involving excess power, radiation, and helium production during D2O electrolysis using palladium cathodes", Fusion Technol. 25, 478, 1994. B. F. Bush, J. J. Lagowski, M. H. Miles, and G. S. Ostrom, "Helium production during the electrolysis of $\mathrm{D}_{2} \mathrm{O}$ in cold fusion", J. Electroanal. Chem. 304 (1991) 271. M. H. Miles, R. A. Hollins, B. F. Bush, J. J. Logowski and R. E. Miles, "Correlation of excess power and helium production during $\mathrm{D}_{2} \mathrm{O}$ and $\mathrm{H}_{2} \mathrm{O}$ electrolysis using palladium cathodes", J. Electroanal. Chem. 346 (1993) 99.

56. B. Bush and J. J. Lagowski, "Methods of generating excess heat with the Pons and Fleischmann effect: Rigorous and cost effective calorimetry, nuclear products analysis of the cathode and helium analysis", Proc. ICCF\%, p. 38 (1998).

57. E. Botta, R. Bracco, T. Bressani, D. Calvo, V. Cela, C. Fanara, U. Ferracin, and F. Iazzi, "Search for ${ }^{4} \mathrm{He}$ production from $\mathrm{Pd} / \mathrm{D}_{2}$ systems in gas phase," Proc. ICCF5, p. 233 (1995).

58. E. Botta, T. Bressani, D. Calvo, C. Fanara, and F. Iazzi, "Measurements of ${ }^{4}$ He production from $\mathrm{D}_{2}$ gasloaded Pd sample," Proc. ICCF6, p. 29 (1996).

59. G. S. Qiao, X. L. Han, L. C. Kong, S. X. Zheng, H. F. Huang, Y. J. Yan, Q. L. Wu, Y. Deng, S. L. Lei, and X. Z. Li, "Nuclear products in a gas-loading D/Pd and H/Pd system", Proc. ICCF7, p. 314 (1998).

60. D. Gozzi, R. Caputo, P. L. Cignini, M. Tomellini, G. Gigli, G. Balducci, E. Cisban, S. Frullani, F. Garibaldi, M. Jodice, G. M. Urciuoli, "Excess heat and nuclear product measurements in cold fusion electrochemical 
cells", Proc. ICCF4, Vol. 1, p. 2-1 (1993).

61. J. O'M. Bockris, C. Chien, D. Hodko, and Z Minevski, "Tritium and Helium Production of Palladium Electrodes and the Fugacity of Deuterium Therein", Proc. ICCF3, p. 231 (1992). C-C Chien, D. Hodko, Z. Minevski and J. O'M. Bockris, "On an electrode producing massive quantities of tritium and helium", J. Electroanal. Chem. 338 (1992) 189.

62. B. Y. Liaw, P.-L. Tao and B. E. Liebert, "Recent progress on cold fusion research using molten salt techniques", Proc. ICCF2, p. 92 (1991).

63. H. Sakaguchi, G. Adachi, and K. Nagao, "Helium Isotopes from Deuterium Absorbed in LaNi5", Proc. ICCF3, p. 527 (1992).

64. J. R. Morrey, M. W. Caffee, H. Farrar, IV, N. J. Hoffman, G. B. Hudson, R. H. Jones, M. D. Kurz, J. Lupton, B. M. Oliver, B. V. Ruiz, J. F. Wacker, and A. Van Veen, "Measurements of helium in electrolyzed palladium", Fusion Technol. 18 (1990) 659.

65. Y. Arata and Y-C. Zhang, "Helium $\left({ }^{4} \mathrm{He},{ }^{3} \mathrm{He}\right)$ within deuterated Pd-black", Proc. Japan Acad. 73B (1997) 1.

66. Y. Arata and Y-C. Zhang, "Achievement of solid-state plasma fusion ("cold fusion"), Proc. Japan Acad. 71 Ser. B (1995) 304.

67. A. G. Lipson, A.S. Roussetski, G.H. Miley, and E.I. Saunin, Proc. ICCF8, p. 231 (2000).

68. A. G. Lipson, A.S. Roussetski, G.H. Miley, and C. H. Castano, Proc. ICCF9, p. 218 (2002).

69. M. H. Miles, "Correlation of excess enthalpy and helium-4 production: A review," Proc. ICCF10, (2004).

70. M.C.H. McKubre, et.al., Energy Production Processes in Deuterated Metals, EPRI Report TR-107843-V1 (1998).

71. F. Cellucci, P. L. Cignini, G. Gigli, D. Gozzi, M. Tomellini, E. Cisbani, S. Frullani, F. Garibaldi, M. Jodice, and G. M. Urciuoli, Proc. ICCF6, p. 3 (1996).

72. A. De Ninno, A. Frattolillo, A. Rizzo and E. Del Giudice, Proc. ICCF9, p. 82 (2002).

73. A. De Ninno, A. Frattolillo, A. Rizzo, and E. Del Giudice, "4 He detection in a cold fusion experiment," Proc. ICCF10, (2004).

74. S. Pons and M. Fleischmann, "Heat after death," Proc. ICCF4, Vol. 2, p. 8-1 (1993).

75. M. Fleischmann and S. Pons, Phys. Lett. A 176118 (1993).

76. M. Bernardini, C. Manduchi, G. Mengoli, and G. Zannoni, "Anomalous effects induced by $\mathrm{D}_{2} \mathrm{O}$ electrolysis at titanium, Proc. ICCF8, p. 39 (2000).

77. M. H. Miles, M. A. Imam, and M. Fleischmann, Proc. ICCF8, p. 105 (2000).

78. M. Fleischmann, Proc. ICCF9, p. III (2002).

79. I. Dardik, H. Branover, A. El-Boher, D. Gazit, E. Golbreich, E. Greenspan,A. Kapusta, B. Khachatorov, V. Krakov, S. Lesin, B. Michailovitch, G. Shani* and T. Zilov, Proc. ICCF10, (2004).

80. M. H. Miles, K. B. Johnson, and M. A. Imam, "Heat and helium measurements using palladium alloys in heavy water," Proc. ICCF6, p. 20 (1996).

81. M. F. Klopfenstein and J. Dash, "Thermal imaging during electrolysis of heavy water with a Ti cathode," Proc. ICCF\%, p. 98 (1998).

82. E. Storms, "Excess power production from platinum cathodes using the Pons-Fleischmann effect," Proc. ICCF8, p. 55 (2000).

83. Y. Arata and Y-C. Zhang, Proc. Japan Acad., 70(B), 106 (1994).

84. S. E. Jones, D. Bennion, D. Buehler, J. B. Czirr, D. L. Decker, J. Harb, R. Hunter, G. L. Jensen, E. P. Palmer, W. Pitt, S. Taylor, J. Thorne, D. Tolley, and J. C. Wang, Proc. Provo meeting, p. 206 (1990).

85. S. E. Jones, T. K. Bartlett, D. B. Buehler, J. B. Czirr, G. L. Jensen, and J. C. Wang, Proc. Provo meeting, p. 397 (1990).

86. F. Celani, A. Spallone, L. Liberatori, B. Stella, F. Ferrarotto, M. Corradi, P. Marini, S. Fortunati, and M. Tului, Proc. Provo meeting, p. 62 (1990).

87. P. I. Golubnichyi, A. D. Philonenko, A. A. Tsaric, E. P. Kovalchuk, G. I. Merzon, and V. A. Tsarev, "Observation of nuclear particles and their correlation with acoustic and electromagnetic emission from palladium targets loaded with deuterium," Proc. Provo meeting, p. 146 (1990).

88. P. I. Golubnichyi, A. D. Philonenko, A. A. Tsaric, V. V. Kuzminov, B. V. Pritchenko, G. I. Merzon, and V. A. Tsarev, "Recording of neutron and acoustic emissions from palladium target in a low background underground experiment," Proc. Provo meeting, p. 151 (1990).

89. M. Okamoto, Y. Yoshinaga, M. Aida, and T. Kusunoki, Proc. ICCF4, Vol. 2, p. 3-1 (1993).

90. S. E. Jones, J. E. Ellsworth and M. R. Scott, F. W. Keeney, A. C. Johnson, D. B. Buehler, F. E. Cecil, G. 
Hubler, and P. L. Hagelstein, "Neutron emissions from metal deuterides," Proc. ICCF10, (2004).

91. K. L. Wolf, "Nuclear reactions in deuterated metals," EPRI Progress Report, March 1992.

92. K. L. Wolf, private communication, 1993.

93. F. E. Cecil, H. Liu, D. Beddingfield, and C. S. Galovich, Proc. Provo meeting, p. 375 (1990).

94. S.E. Jones, F.W. Keeney, A.C. Johnson, D.B. Buehler, F.E. Cecil, G. Hubler, P.L. Hagelstein, J.E. Ellsworth and M.R. Scott, "Charged particle emissions from metal deuterides," Proc. ICCF10, (2004).

95. A. De Ninno, A. Frattolillo, G. Lollobattista, L. Martinis, M. Martone, L. Mori, S. Podda, F. Scaramuzzi, Europhys. Lett. 9221 (1989).

96. A. De Ninno, F. Scaramuzzi, A. Frattolillo, S. Migliori, F. Lanza, S. Scaglione, P. Zeppa, and C. Pontorieri, "The production of neutrons and tritium in the deuterium gas-titanium interaction," Proc. ICCF2, p. 129 (1991).

97. H. O. Menlove, M. A. Paciotti, T. N. Claytor, H. R. Maltrud, O. M. Rivers, D. G. Tuggle, and S. E. Jones, "Reproducible neutron emission measurements from Ti metal in pressurized $\mathrm{D}_{2}$ gas," Proc. Provo meeting, p. 287 (1990).

98. H. O. Menlove, M. A. Paciotti, T. N. Claytor, and D. G. Tuggle, "Low-background measurements of neutron emission from Ti metal in pressurized deuterium gas," Proc. ICCF2, p. 385 (1991).

99. T. Bressani, D. Calvo, A. Feliciello, C. Lamberti, F. Iazzi, B. Minetti, R. Cherubini, A. M. I. Haque, and R. A. Ricci, "A study of the neutron emission from Ti loaded with D in gas phase by means of a time-of-flight spectrometer," Proc. ICCF2, p. 105 (1991).

100. M. Agnello, E. Botta, T. Bressani, D. Calvo, A. Feliciello, P. Gianotti, F. Iazzi, C. Lamberti, B. Minetti, and A. Zecchina, "Measurement of $2.4 \mathrm{MeV}$ neutrons from Ti/D and $\mathrm{Pd} / \mathrm{D}$ systems, Proc. ICCF3, p. 433 (1992).

101. A. De Ninno, F. Scaramuzzi, C. Pontorieri, and P. Zeppa, "Emission of neutron bursts from a titaniumdeuterium gas system in a high-efficiency low-background experimental setup," Proc. Provo meeting, p. 122 (1990).

102. F. Scaramuzzi, "Survey of gas loading experiments," Proc. ICCF2, p. 445 (1991).

103. M. Fleischmann, "An overview of cold fusion phenomena," Proc. ICCF1, p. 344 (1990).

104. D. Gozzi, P. L. Cignini, R. Caputo, M. Tomellini, G. Balducci, G. Gigli, E. Cisbani, S. Frullani, F. Garibaldi, M. Jodice, and G. M. Urciuoli, "Experiments with global detection of cold fusion byproducts," Proc. ICCF3, p. 155 (1992).

105. H. Ogawa, S. Yoshida, Y. Yoshinaga, M. Aida, and M. Okamoto, "Excess heat and neutron emission in Pd-Li-D electrolysis," Proc. ICCF5, p. 116 (1995).

106. A. Takahashi, T. Inokuchi, Y. Chimi, I. Ikegawa, N. Kaji, Y. Nitta, K. Kobayashi, and M. Tanaguchi, "Experimental correlation between heat and nuclear products," Proc. ICCF5, p. 69 (1995).

107. A. Takahashi, "Results of experimental studies on excess heat vs. nuclear products correlation and conceivable reaction model," Proc. ICCF7, p. 378 (1998).

108. Y. Oya, H. Ogawa, M. Aida, K. Iinuma, and M. Okamoto, "Material conditions to replicate the generation of excess energy and the emission of excess neutrons," Proc. ICCF\%, p. 285 (1998).

109. H. Liu, Studies of nuclear reactions $D-D, D-{ }^{6} L i$, and $D_{-}{ }^{10} B$ at low energies and charged particle emission from deuterium-metal systems, PhD Thesis, Colorado School of Mines, 1992.

110. A. G. Lipson, A.S. Roussetski, G.H. Miley, and E.I. Saunin, Proc. ICCF8, p. 231 (2000). A. G. Lipson, A.S. Roussetski, G.H. Miley, and C. H. Castano, Proc. ICCF9, p. 218 (2002).

111. A. G. Lipson, A.S. Roussetski, G.H. Miley, and E.I. Saunin, "Phenomenon of an energetic charged particle emission from hydrogen/deuterium loaded metals," Proc. ICCF10, (2004).

112. J. Kasagi, T. Ohtsuki, K. Ishu and M. Hiraga, Phys. Soc. Japan 64, 777 (1995).

113. E. K. Storms, "A critical evaluation of the Pons-Fleischmann effect", http://www.lenr-canr.org/acrobat/StormsEacriticale.pdf

114. M. Fleischmann, "Thermal and nuclear aspects of the Pd/D2O system; Volume 2", SPAWAR System Center Report TR-1862 (2002).

115. S. Pons and M. Fleischmann, "Calorimetric measurements of the palladium/deuterium system: Fact and fiction", Fusion Technol. 17 (1990) 669.

116. S. E. Jones, L. D. Hansen, S. E. Jones, D. S. Shelton and J. M. Thorne, "Faradaic efficiencies less than $100 \%$ during electrolysis of water can account for reports of excess heat in "cold fusion" cells", J. Phys. Chem. 99 (1995) 6973.

117. F. G. Will "Hydrogen + oxygen recombination and related heat generation in undivided electrolysis cells," 
J. Electroanal. Chem. 426 (1997) 177.

118. M.C.H. McKubre, F. L. Tanzella, P. Tripodi and P. L. Hagelstein, "The emergence of a coherent explanation for anomalies observed in $\mathrm{D} / \mathrm{Pd}$ and $\mathrm{H} / \mathrm{Pd}$ systems: Evidence for ${ }^{4} \mathrm{He}$ and ${ }^{3} \mathrm{He}$ production," Proc. ICCF8, p. 3 (2000).

119. W. B. Clarke, Fusion Science and Technology, "Production of ${ }^{4} \mathrm{He}$ in $\mathrm{D}_{2}$-loaded palladium-carbon catalyst I," 43 (1) 122 (2003).

120. W. B. Clarke, W. J. Jenkins and Z. Top, "Determination of tritium by mass spectrometric measurement of ${ }^{3} \mathrm{He} "$, Int. J. of Appl. Radiat. Isot., 27, p. 515 (1976).

121. Y. Arata and Y-C. Zhang, Proc. Japan Acad., 71(B), 98 (1995).

122. Y. Arata and Y-C. Zhang, Proc. ICCF6, p. 129 (1996).

123. Y. Arata and Y-C. Zhang, J. High Temperature Society, 23, 1 (1997).

124. Y. Arata and Y-C. Zhang, Proc. Japan Acad. 78(B), 57 (2002).

125. Y. Arata and Y-C. Zhang, "Anomalous difference between reaction energies generated within $\mathrm{D}_{2} \mathrm{O}-\mathrm{Cell}$ and $\mathrm{H}_{2} \mathrm{O}-$ cell," Jpn. J. Appl. Phys. 37, L1274 (1998).

126. W. B. Clarke, B. M. Oliver, M.C.H. McKubre, F. L. Tanzella and P. Tripodi, "Search for ${ }^{3} \mathrm{He}$ and ${ }^{4} \mathrm{He}$ in Arata-style palladium cathodes II; Evidence for tritium production", Fusion Science and Technology, 40 (2) (2001).

127. Y. Arata and Y-C. Zhang, "Deuterium nuclear reaction process within solid," Proc. Japan Acad. 72(B), 179 (1996).

128. Y. Arata and Y-C. Zhang, "Presence of Helium $\left({ }^{4} \mathrm{He},{ }^{3} \mathrm{He}\right)$ confirmed in deuterated Pd-black by the 'vieffect' in a 'closed QMS' environment," Proc. Japan Acad. 73B, 62 (1997).

129. Y. Arata and Y-C. Zhang, "Anomalous production of gaseous ${ }^{4} \mathrm{He}$ at the inside of 'DS-cathode' during $\mathrm{D}_{2}$ O-electrolysis," Proc. Japan Acad. 75B, 281 (1999).

130. A. Farkas, "On the electrolytic separation of the hydrogen isotopes on a palladium eathode," Trans. Faraday Soc. 33, 552 (1937).

The conference proceedings cited in this bibliography are:

Proc. Provo meeting (1990):

Anomalous Nuclear Effects in Deuterium/Solid Systems, Provo, UT 1990, American Institute of Physics: Conference Proceedings, edited by S.E Jones, F. Scaramuzzi, and D.H. Worledge, 228.

Proc. ICCF1 (1990):

Proceedings of the First International Conference on Cold Fusion, Mar. 1990 Salt Lake City, UT, edited by F. Will.

Proc. ICCF2 (1991):

The Science of Cold Fusion, Proc. of the Second Annual Conference on Cold Fusion, Como, Italy, June 29-July 4, 1991, edited by T. Bressani, E. Del Giudice and G. Preparata, Published by Societa Italiana di Fisica, 33.

Proc. ICCF3 (1993):

Frontiers of Cold Fusion, Proceedings of the Third International Conference on Cold Fusion, Oct. 1992 Nagoya, Japan, edited by H. Ikegami, Universal Academy Press, Tokyo.

Proc. ICCF4 (1993):

Proceedings of the Fourth International Conference on Cold Fusion, Dec. 1993 Maui, Hawaii, edited by T. O. Passell and M. C. H. McKubre.

Proc. ICCF5 (1995):

Proceedings of the Fifth International Conference on Cold Fusion, Monte Carlo, Monaco April 9-13, 1995, IMRA Europe, Sophia Antipolis Cedex, France (1995). 
Proc. ICCF6 (1996):

Proceedings of the Sixth International Conference on Cold Fusion, October 1996 Hokkaido, Japan, edited by M. Okamoto.

Proc. ICCF'7 (1998):

Proceedings of The Seventh International Conference on Cold Fusion, Vancouver, Canada, April 19-24, 1998, ENECO, Inc., Salt Lake City, UT (1998).

Proc. ICCF8 (2000):

Proceedings of the Eighth International Conference on Cold Fusion, May 2000 Lerici (La Spezia), Italy, edited by F. Scaramuzzi.

Proc. ICCF9 (2002): Proceedings of the Ninth International Conference on Cold Fusion, May 2002 Beijing, China, edited by X. Z. Li.

Proc. ICCF10 (2003): Proceedings of the Tenth International Conference on Cold Fusion, August 2003 Cambridge, MA, edited by P. L. Hagelstein and S. R. Chubb, World Scientific, to appear. 